\title{
THERMODYNAMIC PROPERTIES OF 9-METHYLCARBAZOLE AND
}

\section{1,2,3,4-TETRAHYDRO-9-METHYLCARBAZOLE}

Topical Report

By

W. V. Steele

S. E. Knipmeyer
A. Nguyen
R. D. Chirico

April 1991
NIPER- -520

DE91 002235

Work Performed Under Cooperative Agreement No. DE-FC22-83FE60149

\section{Prepared for}

U.S. Department of Energy

Assistant Secretary for Fossil Energy

\author{
W. D. Peters, Project Manager \\ Bartlesville Project Office \\ P.O. Box 1398 \\ Bartlesville, OK 74005
}

Prepared by

IIT Research Institute

National Institute for Petroleum and Energy Research

P. O. Box 2128

Bartlesville, OK 74005 


\section{EXECUTI VE SUMM ARY}

Events in the Persian Gulf have highlighted yet again the fragility of the continuity of supplies of Arabian crude oil to U.S. refineries. Successive "oil crunches" have initiated discussion of ways to decrease the U.S.A.'s dependence on so valuable a resource from such a volatile area of the world. Political considerations, such as the possibility of a Americas Free Market encompassing the whole American continent (similar to the European Economic Community), could entail more extensive use of "local" oil supplies. However, much of the "local" supplies are classified as heavy petroleums; e.g., California Wilmington, Mexican Mayan, and Venezuelan Cerro Negro and Boscan. These heavy crudes each contain more heteroatoms (nitrogen in particular), more aromatics and less long-chain saturated hydrocarbons than Arabian light crude.

Even without the political considerations, the picture of crude oil refining in the U.S.A. has changed considerably in the last ten years. The world supply of petroleum crude and light petroleum crude in particular, continues to decline. The density and, hence, complexity of refinery feedstocks have increased markedly in the last decade. The average API gravity of the crude oil run to stills in the United States dropped from approximately 34.2 in 1978 to 32.0 in 1989. That drop in API gravity has been accompanied by an equivalent increase in the amount of petroleum coke exported by the United States. When the cost of the oil imported and the price obtained for the coke are compared, it accounts for approximately one billion dollars of the trade balance deficit per year. The need for new technological advances in the processing of heavy petroleum is evident.

Catalytic hydrodesulfurization (HDS) is a key step in upgrading processes for conversion of light petroleum to economically viable products. Due to the increased nitrogen content of heavy petroleums relative to light crudes, catalytic hydrodenitrogenation (HDN) is a key step in their refining. Present HDN technology can be summarized as being HDS technology but with a "much increased severity." Organic nitrogen is commonly removed via reaction at 300 to $400^{\circ} \mathrm{C}$ and 50 to $150 \mathrm{~atm}$. of hydrogen. Under these severe conditions, hydrogen is consumed not only in breaking carbon-nitrogen bonds but also in saturating aromatic components in the feed. Hydrogen consumption in excess of $1500 \mathrm{scf} / \mathrm{bbl}$ (standard cubic feet per barrel) is common in such hydrotreating situations, while the amount theoretically required for selective heteroatom removal is only about $600 \mathrm{scf} / \mathrm{bbl}$. Hence, the saving in expensive hydrogen could be enormous if a process for denitrogenation without saturation of the aromatic rings in the feedstock could be developed.

This research program, funded by the Department of Energy (DOE) Office of Fossil Energy, Advanced Extraction and Process Technology (AEPT), provides accurate experimental thermochemical and thermophysical properties for "key" organic nitrogen-containing compounds present in heavy petroleum feedstocks, and applies the experimental information to thermodynamic analyses of key HDN reaction networks 
(e.g., quinoline/hydrogen, indole/hydrogen, and in this case carbazole/hydrogen). Thermodynamic analyses, based on accurate information, provide insights for the design of cost-effective methods of nitrogen removal.

Removal of carbazole and its derivatives from heavy petroleum has proved to be particularly difficult using present technology. Studies have shown carbazole and its alkyl-homologs are the dominant nitrogen-containing components in clarified slurry oils, thereby indicating their low reactivity and/or formation during cat-cracking processes. According to the results of some studies, carbazoles survive the various refining processes and end up in the finished products, which leads to gum formation and low thermal stability. The results reported here, and in a companion report to be completed in April 1991, will point the way to the development of new methods of nitrogen removal from carbazole and its derivatives.

This report details the thermodynamic properties of 9-methylcarbazole and 1,2,3,4-tetrahydro-9-methylcarbazole. The thermodynamic properties were measured using adiabatic heat-capacity calorimetry, differential-scanning calorimetry (d.s.c.), comparative ebulliometry, inclined-piston gauge manometry, and combustion calorimetry. Critical properties were estimated from thermodynamic principles. All measured properties were combined to derive Gibbs energies of formation for a range of temperatures. With these Gibbs energies, sufficient information is now available for a comprehensive thermodynamic analysis of the carbazole/hydrogen reaction network. This analysis will be published as the next topical report within this research program.

In addition to providing the concrete base for the upcoming thermodynamic analysis, the properties reported here are particularly useful to the process-design engineer. These results, in conjunction with values for other major nitrogencontaining compound types studied in this project, form a soliild base for the development of process design correlations. Such correlations are necessary for the cost-effective, energy-efficient design of process equipment such as distillation towers, heat. exchangers, and gas-liquid reactors. A major risk associated with the lack of thermodynamic data is possible extensive derating of a plant because of undersized equipment. For example, if heat duties or vapor flow rates are underestimated during design, the installed equipment will be unable to accommodate the process streams at design flow rates resulting in less than economic operation of the plant. 


\begin{abstract}
Measurements leading to the calculation of the ideal-gas thermodynamic properties are reported for 9-methylcarbazole and 1,2,3,4-tetrahydro-9-methylcarbazole. For studies on 1,2,3,4-tetrahydro-9-methylcarbazole experimental methods included combustion calorimetry, adiabatic heat-capacity calorimetry, vibrating-tube densitometry, comparative ebulliometry, incliried-piston gauge manometry, and differential-scanning calorimetry (d.s.c.). Adiabatic heat-capacity and combustion calorimetric studies were reported previously for 9-methylcarbazole. Vapor pressures by comparative ebulliometry and inclined-piston gauge manometry, and heat-capacities for the liquid phase by d.s.c. are reported here. Entropies, enthalpies, and Gibbs energies of formation were derived for the ideal gas for both compounds for selected temperatures between $298.15 \mathrm{~K}$ and near $700 \mathrm{~K}$. The Gibbs energies of formation will be used in a subsequent report in thermodynamic calculations to study the reaction pathway of the initial hydrogenation step in the carbazole $/ \mathrm{H}_{2}$ hydrodenitrogenation network.
\end{abstract}

\title{
ACKNOWLEDGEM ENTS
}

The authors gratefully acknowledge the financial support of the Office of Fossil Energy of the U.S. Department of Energy. This research was funded within the Advanced Extraction and Process Technology (AEPT) program as part of the Cooperative Agreement DEFC22-83FE60149.

The authors acknowledge Professor E. J. "Pete" Eisenbraun and his research, group at Oklahoma State University for preparation of the samples, and the assistance of 1. Alex Hossenlopp in vapor-transfer of the materials prior to the calorimetric measurements. 
TABLE OF CONTENTS

Executive Summary

Absiract

Acknowledgements

Table of Contents

List of Tables

List of Figures

Glossary

1. Invoduction

2. Experimental

Materials

Physical Constants and Standards

Appraratus and Procedures

Combustion Calorimetry

Densitometry

iv

Ebulliometric Vapor-Pressure Measurements 6

Inclined-Piston Vapor-Pressure Measurements 6

Adiabatic Heat-Capacity Calorimetry 7

Differential Scanning Calorimetry (d.s.c.)

3. Results

Combustion Calorimetry $\quad 7$

Density Measurements 9

Vapor-Pressure Measurements 9

Cox Equation Fits to Vapor Pressures $\quad 9$

Derived Enthalpies of Vaporization 10

Adiabatic Heat-Capacity Calorimetry 11

Crystallization and Melting Studies $\quad 11$

Phase Transformations and Enthalpy Measurements 11

Heat-Capacity Measurements 12

Differential Scanning Calorimetry 17

Theoretical Background 17

Thermodynamic Properties in the Condensed State 19

Thermodynamic Properties in the Ideal-Gas State 20

Calculation of Sublimation Pressures 21

4. Discussion 21

Comparison of Results with Literature $\quad 21$

5. Summary and Highlights 23

6. References 24 


\section{LIST OF TABLES}

TABLE 1. Calorimeter and sample characteristics

Page

TABLE 2. Typical combustion experiment at $298.15 \mathrm{~K}$

26

TABLE

4. Summary of energies of combustion and molar thermochemical functions for 1,2,3,4-tetrahydro-9-methylcarbazole

TABLE 2. Measured densities of 1,2,3,4-tetrahydro-9-methylcarbazole at saturation pressure

TABLE

5. Vapor-pressure results

TABLE

6. Cox equation coefficients

TABLE

7. Enthalpies of vaporization

TABLE

8. Melting-study summary

TABLE

9. Molar enthalpy measurements

TABLE 10. Molar heat capacities at vapor-saturation pressure

TABLE 11. Experimental $C_{x, m}^{\prime \prime} / R$ values

TABLE 12. Parameters for equations (13) and (14) and estimated critical constants

TABLE 13. Values of $C_{v, m}^{\prime l}\left(\rho=\rho_{\text {sat }}\right) / R$ and $C_{\text {sat }, m} / R$

TABLE 14. Molar thermodynamic functions at vapor-saturation pressure

TABLE 15. Thermodynamic properties in the ideal-gas state

\section{LIST OF FIGURES}

FIGURE 1. Initial pathways in the hydrodenitrogenation of carbazole

FIGURE 2. Molecular structure of the compounds studied in this research

FIGURE 3. Synthesis route to 1,2,3,4-tetrahydro-9-methylcarbazole

FIGURE 4. Synthesis route to 9-methylcarbazole

FIGURE 5. Heat capacity against temperature

for 1,2,3,4-tetrahydro-9-methylcarbazole

FIGURE 6. Average heat capacities in the $\operatorname{cr}(11)-\operatorname{to}-\operatorname{cr}(1)$ transition region for 1,2,3,4-tetrahydro-9-methylcarbazole

FIGURE 7. Average heat capacities in the $\mathrm{cr}(I I I)-t 0-\mathrm{cr}(\mathrm{II})$ transition region for 1,2,3,4-tetrahydro-9-methylcarbazole

FIGURE 8. Average heat capacities in the $\operatorname{cr}(\mathrm{IV})-\mathrm{to}-\mathrm{cr}$ (III) transition region for 1,2,3,4-tetrahydro-9-methylcarbazole

FIGURE 9. Parity plot comparing sublimation pressures measured by Jiménez et al. with values calculated using equation (19) 


\section{GL OSSARY}

This report is written with close adherence to the style adopted by The Journal of Chemical Thermodynamics. A complete description of the style can be found in the January 1991 issue of the journal. This glossary summarizes the main points with respect to the symbol usage.

Throughout this report only $S I$ units are used in reporting thermodynamic values. All values are given in dimensionless units i.e., physical quantity $=$ number $X$ unit; for example $\rho /\left(\mathrm{kg} \cdot \mathrm{m}^{-3}\right)$ rather than " $\rho\left(\mathrm{kg} / \mathrm{m}^{3}\right)$ " or " $\rho \mathrm{kg} / \mathrm{m}^{3}$ ". Molar values, i.e., intensive functions, are denoted by the subscript "m", e.g., $C_{\text {sat, }} m$, whereas extensive functions do not have the subscript. In addition, since thermodynamic values are pressure dependent, they are reported in terms of a standard pressure $\mathrm{p}^{\circ}$, which in this report is $101.325 \mathrm{kPa}$ (one atmosphere).

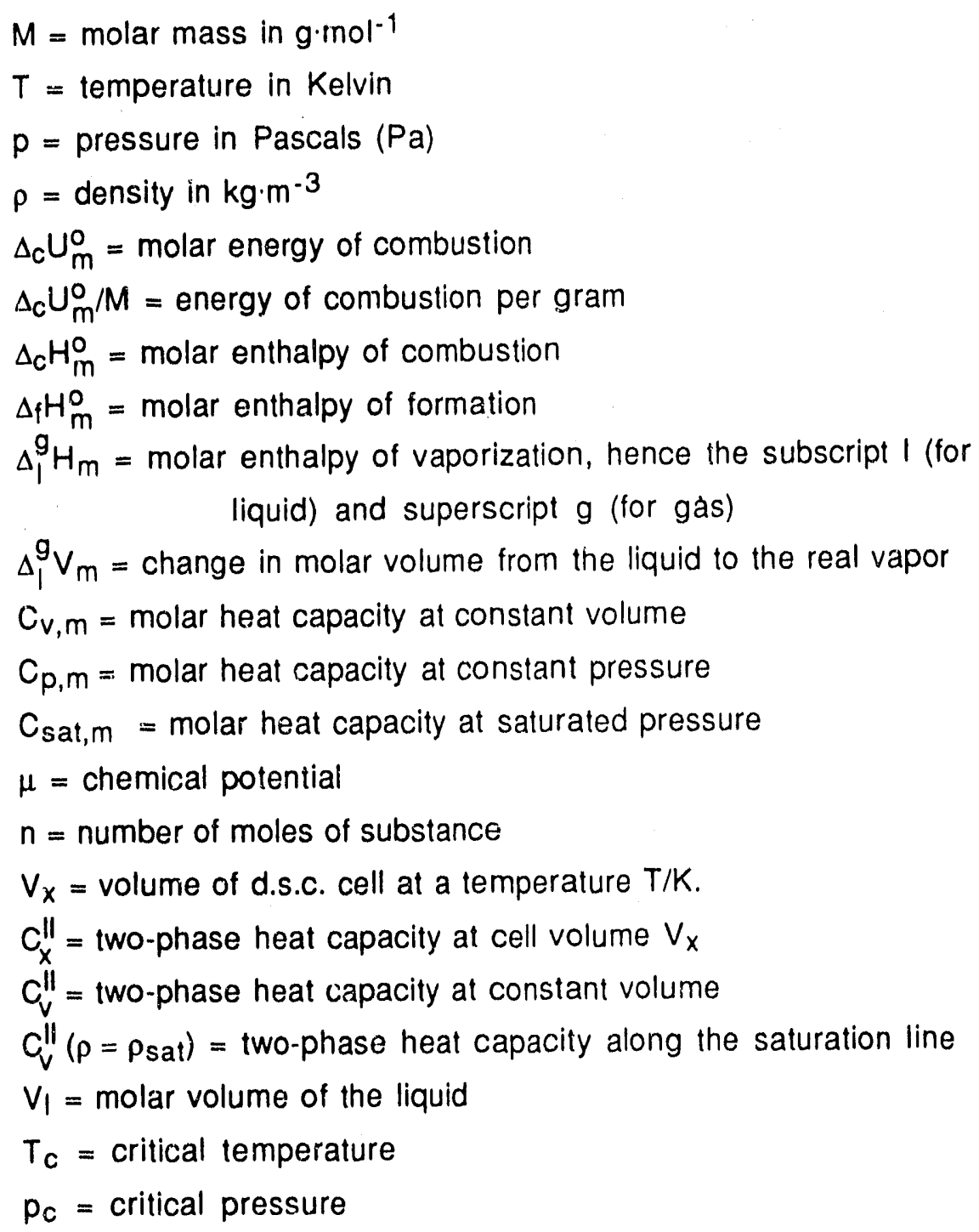


$\rho_{c}=$ critical density

$T_{r}=$ reduced temperature $=T / T_{C}$

$\mathrm{p}_{\mathrm{r}}=$ reduced pressure $=\mathrm{p} / \mathrm{p}_{\mathrm{c}}$

$\rho_{r}=$ reduced density $=\rho / \rho_{c}$

$\lg =\log 10$

$\omega=$ acentric factor $=\left[-\lg \left(p_{x} / p_{c}\right)-1\right] ; p_{x}$ is the vapor pressure at $T_{r}=0.7$ $\Delta_{0}^{T} S_{m}^{0}=$ molar entropy at temperature $T / K$ (relative to the entropy at $T=0 \mathrm{~K}$ ) $\Delta_{0}^{\top} H_{m}^{0}=$ molar enthalpy at temperature $T / K$ (relative to the crystals at $0 \mathrm{~K}$ )

$\Delta_{c o m p} S_{m}=$ molar entropy of compression of a gas

$\Delta_{i m p} S_{m}=$ gas imperfection term

$T \rightarrow 0=$ Zero Kelvin

To avoid listing units in tables, entropies are reported as divided by the gas constant $R$, and enthalpies and Gibbs energies are generally reported divided by the product of the gas constant and temperature, R.T. Units of time are $s$ (seconds) or h (hours). 


\section{INTRODUCTION}

In this research program, funded by the Department of Energy (DOE) Office of Fossil Energy, Advanced Extraction and Process Technology. (AEPT), thermochemical and thermophysical properties are determined for "key" organic nitrogen-containing compounds present in heavy petroleum, shale oil, tar sands, and the products of the liquefaction of coal. Catalytic hydrodenitrogenation (HDN) is a key step in the upgrading of these feedstocks. $(1-4) \S$ They ars typically rich in nitrogen, and their fractionation produces distillates that are also rich in nitrogen, thus giving poor-quality distillate fuels without denitrogenation.

Hydrodenitrogenation (HDN) reaction systems for aromatic compounds contain steps where the aromatic ring structures are hydrogenated. These reaction steps are all reversible within the temperature and pressure ranges of hydrogenation reactors used commercially. Therefore, a knowledge of the thermodynamic equilibria among the species is necessary for the proper interpretation of reaction data, for comparing different catalysts, and for accurate modelling of the overall reaction. In addition a knowledge of the thermophysical properties (vapor pressures, heat capacities, densities, etc.) is necessary for process-design engineering.

Oversaturation of rings is a common problem in the HDN of aromatic compounds. Therefore, to minimize consumption of expensive hydrogen in processing, the itDN pathway involving the most efficient use of hydrogen is sought. The problem of oversaturation in the HDN of aromatics is exacerbated as the number of rings increases. This research group has reported thermodynamic analyses of the indole/hydrogen (5) and quinoline/hydrogen(6) networks. This report is the second in a series that will lead to an analysis of a three-ring system; the carbazole/hydrogen HDN network. The thermodynamic properties of 2-aminobiphenyl were reported previously in NIPER-482.(7)

2-Aminobiphenyl is the first feasible hydrogenolysis (i.e., ring opened) product in the HDN network for carbazole. In NIPER-482 thermodynamic equilibria calculations showed that carbazole was less reactive for direct hydrogenolysis than either fluorene or dibenzofuran, two similarly structured compounds. That report also concluded that for the HDN of carbazole, the reaction pathway using the minimum of hydrogen (carbazole $\rightarrow 2$-aminobiphenyl $\rightarrow$ biphenyl) probably cannot be realized.

$\S$ References are listed in numerical order at the end of this report. 
However, the pathway (carbazole $\rightarrow$ 2-aminobiphenyl $\rightarrow$ 2-phenylcyclohexylamine $\rightarrow$ cyclohexylbenzene) should be possible with proper catalyst selection.

If hydrogenolysis is preceded by ring saturation, the initial stable compound formed in the HDN of carbazole is 1,2,3,4-tetrahydrocarbazole, which may then undergo further hydrogenation and hydrogenolysis to form 2-cyclohexylaniline. This HDN reaction pathway consumes four moles of hydrogen to reach the same stage on the pathway to nitrogen removal (i.e., one of the two $\mathrm{C}-\mathrm{N}$ bonds broken) as that reached using the one mole to form 2-aminobiphenyl. Figure 1 shows the initial steps in the two pathways.
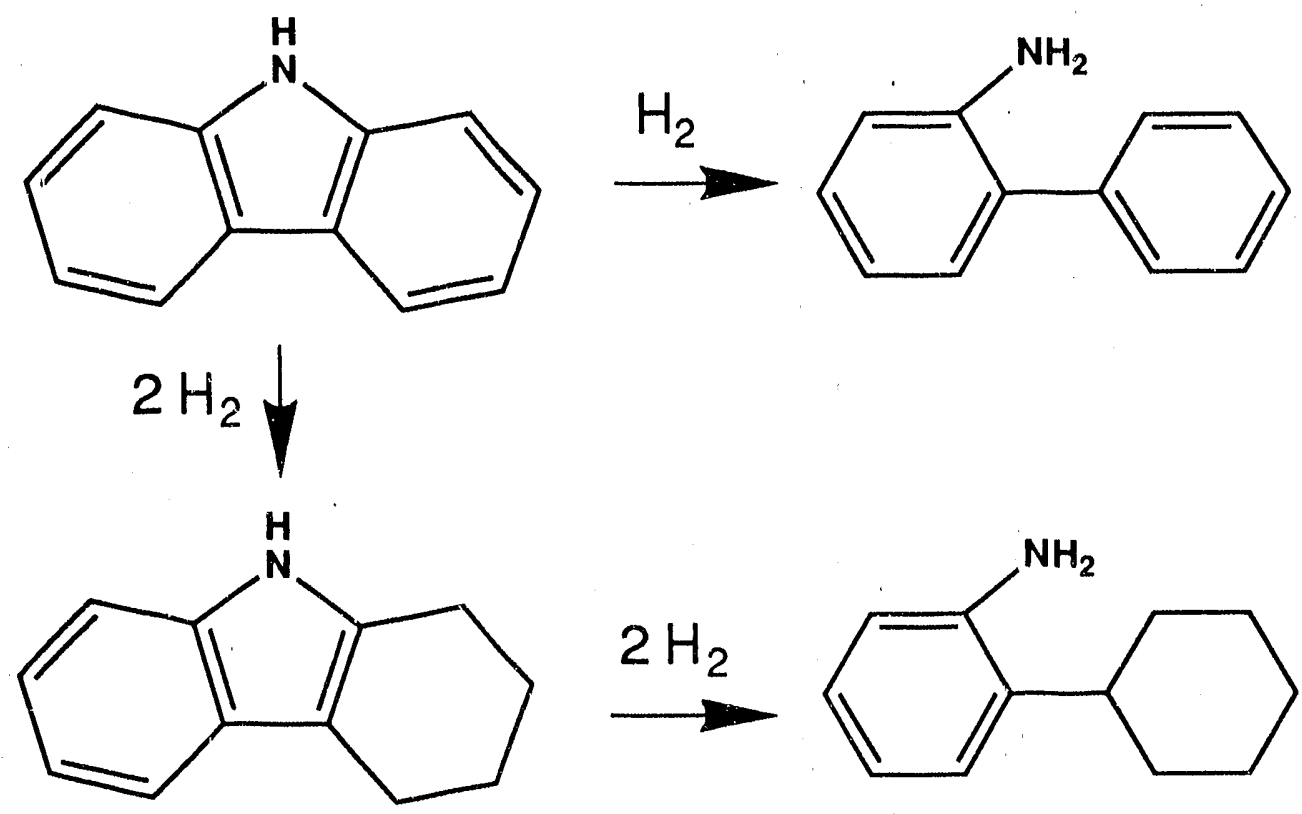

FIGURE 1. Initial pathways in the hydrodenitrogenation of carbazole.

Calculations of the thermodynamic equilibria obtained as the HDN reaction follows the ring saturation/hydrogenolysis pathway require a knowledge of the Gibbs energies of formation of carbazole and its hydrogenation products. Due to its high melting point $(521 \mathrm{~K})$, direct thermodynamic-property measurements on carbazole are not possible using the available equipment at NIPER. However, with measurements on a suitably chosen substituted carbazole derivative, the necessary properties for the parent compound can be estimated reliably with the methods of group additivity. ${ }^{(8)}$ Substitution of a methyl group on the 9 position (i.e., the nitrogen atom) provides an ideal derivative for both measurements and subsequent reliable group-additivity estimates on the parent compound. In this report, measurements leading to the thermodynamic properties of 9-methylcarbazole and its initial stable hydrogenation 
product, 1,2,3,4-tetrahydro-9-methylcarbazole, are described. The compounds are shown in figure 2.
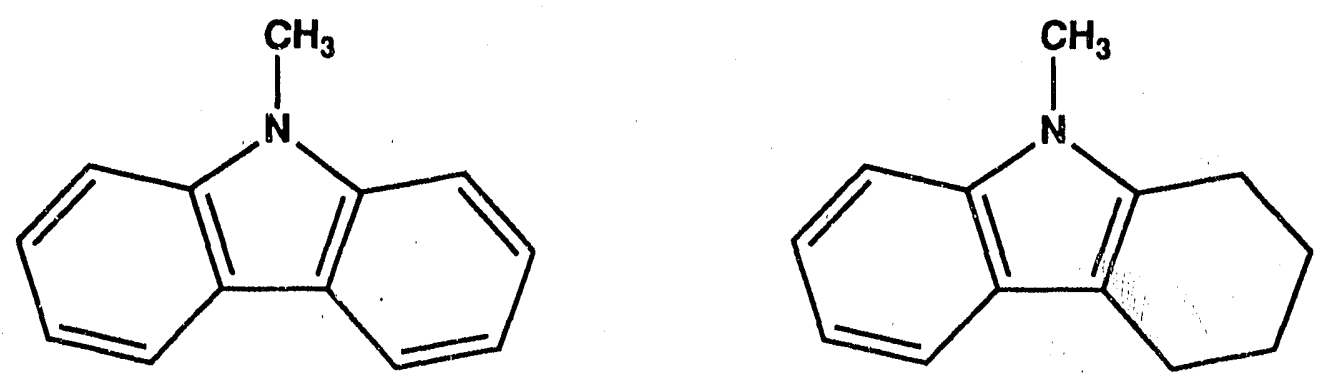

FIGURE 2. Compounds studied in this research.

\section{EXPERIMENTAL}

\section{MATERIALS}

The synthesis route for 1,2,3,4-tetrahydro-9-methylcarbazole is shown in figure 3 . A mixture of $1.1 \mathrm{~mol}$ of cyclohexanone and $6.6 \mathrm{~mol}$ of acetic acid contained in a $2 \mathrm{dm}^{3}$, three-necked flask equipped with a reflux condenser, magnetic stirrer, and addition funnel was stirred and heated under reflux. To this hot solution, 1.1 mol of 1 -methyi1-phenylhydrazine was added during $1 \mathrm{~h}$. The mixture was refluxed for an additional hour and then poured into an ice-water mixture. The precipitated solid was filtered and washed with waier. The crude dark-brown solid was air dried to give $198 \mathrm{~g}$ ( 97 per cent yield). It was Soxhlet-extracted through a bed of neutral and basic alumina with petroleum ether to give $152 \mathrm{~g}$ of 1,2,3,4-tetrahydro-9-methylcarbazole (76 per cent yield). Purification was accomplished though formation of the picrate derivative, its recrystallization from methanol, and subsequent cleavage by extraction through basic alumina using $\mathrm{n}$-hexane.<smiles>CN(N)c1ccccc1</smiles>

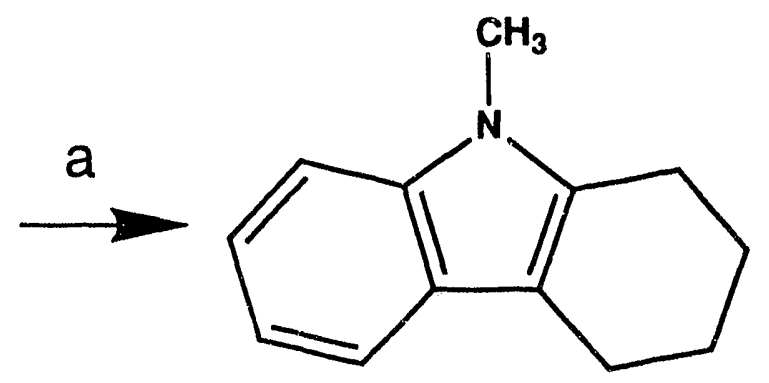

FIGURE 3. Synthesis route to 1,2,3,4-tetrahydro-9-methylcarbazole; a Acetic acid, $\Delta$. 
The mole-fraction impurities for 1,2,3,4-tetrahydro-9-methylcarbazole were estimated by g.l.c. to be 0.0007 . The mole-fraction impurities of the calorimetric sample were found to be slightly higher in fractional-melting studies completed as part of the adiabatic heat-capacity studies. The mole-fraction of impurities determined in the fractional-melting studies was 0.0015 . This higher impurity value is believed to be more reliable than the g.l.c. result.

Previously reported calorimetric studies on 9-methylcarbazole performed at this laboratory $(9.10)$ were completed on samples prepared as part of American Petroleum Institutu (API) Project 52. The 9-methylcarbazole samples used in the research reported here were synthesized by the route shown in figure 4. For step "a," cyclohexanone $(1.5 \mathrm{~mol})$ and acetic acid $(9 \mathrm{~mol})$ were combined and heated to reflux as described above. Phenylhydrazine $(1.5 \mathrm{~mol})$ was added dropwise to this hot solution. After $1 \mathrm{~h}$ of additional reflux, the product was allowed to crystallize and was filtered. The solid product was washed with water and ethanol. The crude 1,2,3,4-tetrahydrocarbazole was recrystallized from methanol, and a total of $173 \mathrm{~g}$ was recovered (67 per cent yield).

Step " $b$ " in figure 4 was accomplished by treating the purified 1,2,3,4-tetrahydrocarbazole with $10 \mathrm{~g}$ of 5 per cent $\mathrm{Pd} / \mathrm{C}$ catalyst in $0.5 \mathrm{dm}^{3}$ of refluxing 1,2,4-trimethylbenzene. After $3 \mathrm{~h}, 2 \mathrm{~g}$ of catalyst were added and reflux was continued for four additional hours. The reaction was cooled and $1.5 \mathrm{dm}^{3}$ of acetone was added to dissolve carbazole, and the catalyst was removed by filtration. Acetone was distilled, petroleum ether (boiling range $311 \mathrm{~K}$ io $316 \mathrm{~K}$ ) was added, and solid carbazole was filtered as a colorless solid.

Step" "c" of figure 4 was performed by dissolution of the carbazole $(1.08 \mathrm{~mol})$ in $0.9 \mathrm{dm}^{3}$ acelone and dimethylsulfate $(1.92 \mathrm{~mol})$ was added in one portion. A solution of sodium hydroxide $(4.5 \mathrm{~mol})$ in vialer $\left(0.12 \mathrm{dm}^{3}\right)$ was added dropwise over $0.3 \mathrm{~h}$ to the stirred mixture. Aftei $2 \mathrm{~h}$ of stirring, the reflux product mixture was cooled and poured into an ice-water mixture. Crude 9-methylcarbazole precipitated $(1.08 \mathrm{~mol})$. Purification was accomplished by Soxhlet extraction through basic alumina with petroleum ether (boiling range $318 \mathrm{~K}$ to $323 \mathrm{~K}$ ). Crystallization from petroleum ether gave $0.8 \mathrm{~mol}$ of 9-methylcarbazole. Analysis of the purified 9-methylcarbazole by g.l.c. showed the mole fraction impurities to be less than 0.0001 . The high purity of the sample was corroborated by the small differences between the boiling and condensation temperatures observed in the ebulliometric vapor-pressure studies. 

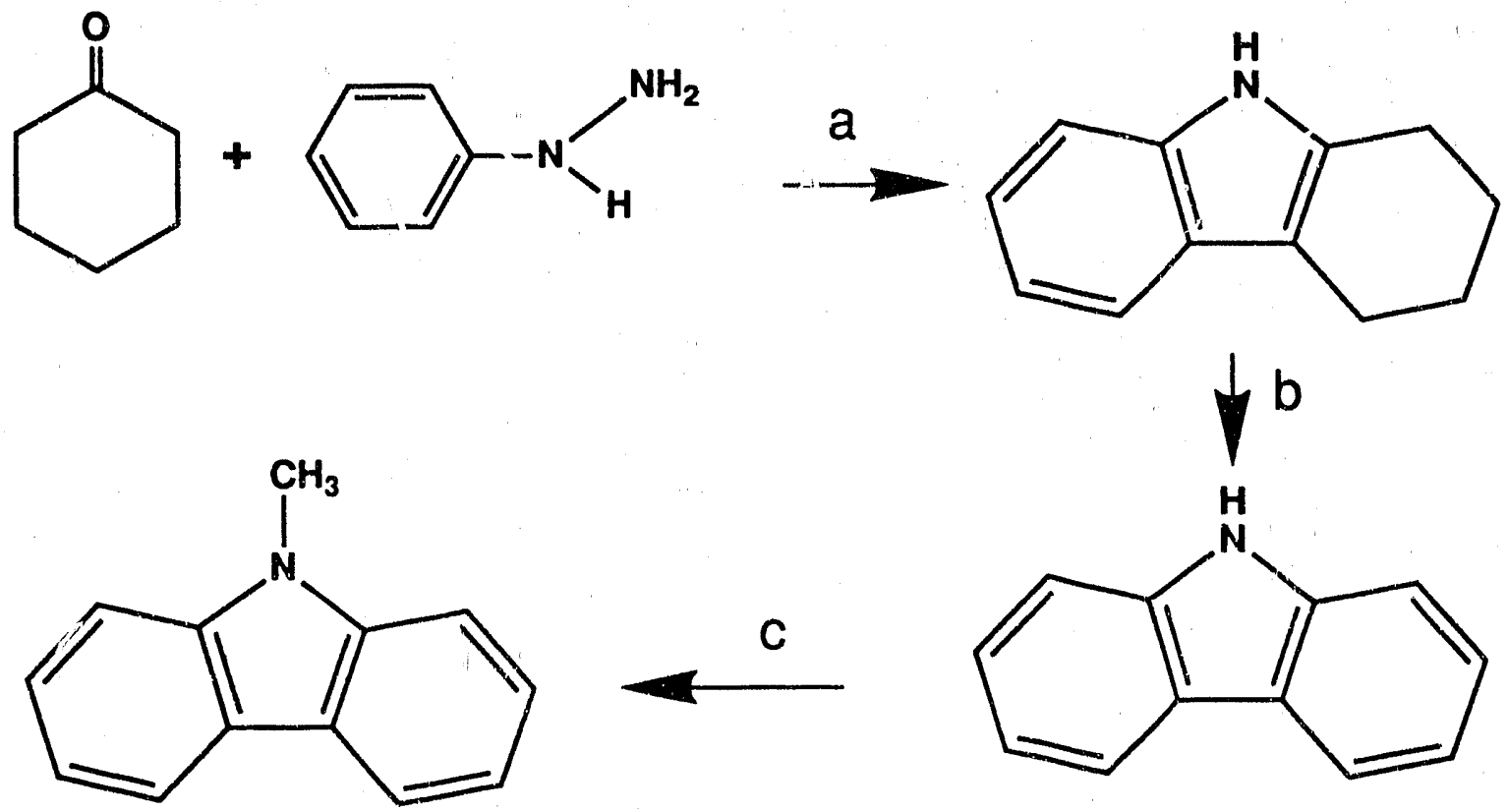

FIGURE 4. Synthesis route to 9-methylcarbazole:

a Acetic acid, $\Delta ;{ }^{b} \mathrm{Pd} / \mathrm{C}, 1,2,4$-trimethylbenzene, $\Delta ;{ }^{c}$ Dimethylsulfate, aa. $\mathrm{NaOH}$, acetone, $\Delta$.

The water used as a reference material in the ebulliometric vapor-pressure measurements was deionized and distilled from potassium permanganate. The decane used as a reference material for the ebulliometric measurements was purified by urea cormplexation, two recrystallizations of the complex, its decomposition with water, extraction with ether, drying with $\mathrm{MgSO}_{4}$, and distiliation at $337 \mathrm{~K}$ and $1 \mathrm{kPa}$ pressure.

\section{PHYSICAL CONSTANTS AND STANDARDS}

Molar values are reported in terms of $M=185.269 \mathrm{~g} \cdot \mathrm{mol}^{-1}$ and $181.237 \mathrm{~g} \cdot \mathrm{mol}^{-1}$ for 1,2,3,4-tetrahydro-9-methylcarbazole and 9-methyicarbazole, respectively, based on the relative atomic masses of $1981(11) \dagger$ and the gas constant $\mathrm{R}=8.31451 \mathrm{~J} \cdot \mathrm{K}^{-1} \cdot \mathrm{mol}^{-1}$ adopted by CODATA.(12) The platinum resistance thermometers used in these measurements were calibrated by comparison with standard thermometers whose constants were determined at the National Institute of Standards and Technology (NIST), formerly the National Bureau of Standards (NBS). All temperatures reported are in terms of the IPTS-68.(13) The platinum resistarce thermometer used in the adiabatic heat-capacity studies was calibrated below $13.81 \mathrm{~K}$ with the method of

† The 1981 relative atomic masses were used because the CODATA Recommended Key Values for Thermodynamics (reference 36 ) are based on them. 
McCrackin and Chang.(14) Nieasurements of mass, time, electrical resistance, and potential difference were made in terms of standards traceable to calibiations at NIST.

\section{APPARATUS AND PROCEDURES}

Combustion Calorimetry. The experimental procedures used in the combustion calorimetry of organic nitrogen comipounds at the National Institute for Petroleum and Energy Research have been describcd.i.5-17) A rotating-bomb calorimetei (laboratory designation BMR II) ${ }^{(18)}$ and platinum-lined bomb (laboratory designation $\left.\mathrm{Pt}-3 \mathrm{~b}\right)(19)$ with an internal volume of $0.3934 \mathrm{dm}^{3}$ were used withuut rotation.

Temperatures were measured by quartz-crystal thermometry. $(20,21) \quad A$ computer was used to control the combustion experiments and record the results. The quartz-crystal thermometer was calibrated by comparison with a platinum resistance thermometer. Counts of the crystal oscillation were taken over periods of $100 \mathrm{~s}$ throughout the experiments. Integration of the time-temperature curve is inherent in the quartz-crystal thermometer readings.(22)

Densitometry. The densitometry apparatus and measurement procedures employed have been described.(23)

Ebulliometric Vapor-Pressure Measurements. The essential features of the ebuiliometric equipment and procedures are described in the literature. $(24,25)$ The ebulliometers were used to reflux the substance under study with a standard of known vapor pressure under a common helium atmosphere. The boiling and condensation temperatures of the two substances were determined, and the vapor pressure was derived with the condensation temperature of the standard. (26)

The precision in the temperature measurements for the ebulliometric vapor. pressure studies was $0.001 \mathrm{~K}$. The precision in pressure is adequately described by:

$$
\sigma(p)=(0.001 K)\left\{\left(d p_{r e f} / d T\right)^{2}+\left(d p_{x} / d T\right)^{2}\right\}^{1 / 2},
$$

where $p_{r e f}$ is the vapor pressure of the reference substance and $p_{x}$ is the vapor pressure of the sample under study. Values of $d p_{r e f} / d T$ tor lile reference substances were calculated from fits of the Antoine equation(27) to vapor pressures of the reference materials (decane and water) reported in reference 26 .

Inclined-Piston Vapor-Pressure Measurements. The equipment for the inclined-piston vapor-pressure measurements has been described by Douslin and $M^{C} C u l l o u g h,(28)$ and Douslin and Osborn.(29) Recent revisions to the equipment and procedures have been 
reported.(23) Uncertainties in the pressures determined with the inclined-piston apparatus, on the basis of estimated precision of measuring the mass, area, and angle of inclination of the piston, are adequately described by the expression:

$$
\sigma(p)=1.5 \times 10^{-4} p+0.2 \mathrm{~Pa} .
$$

The uncertainties in the temperatures are $0.001 \mathrm{~K}$.

Adiabatic Heat-Capacity Calorimetry. Adiabatic heat-capacity and enthalpy measurements were made with a calorimetric system described previously. (23) The calorimeter characteristics and sealing conditions are given in table 1. I Energy measurement procedures were the same as those described for studies on quinoline.(23) Thermometer resistances were measured with self-balancing, alternating-current resistance bridges ( $H$. Tinsley \& Co. Lid.; Models $5840 \mathrm{C}$ and 5840D). Energies were measured to a precision of 0.01 per cent, and temperatures were measured to a precision of $0.0001 \mathrm{~K}$. The energy increments to the filled platinum calorimeter were corrected for enthalpy changes in the empty calorimeter, for the helium exchange gas, and for vaporization of the sample. The maximum correction to the measured energy for the helium exchange gas was 0.1 per cent near $5 \mathrm{~K}$. The sizes of the other two corrections are indicated in table 1.

Differential-Scanning Calorimetry (d.s.c.). Differential-scanning calorimetric measurements were made with a Perkin-Elmer DSC-2. Experimental methods were described previously. $(30-32)$

\section{RESULTS}

COMBUSTION CALORIMETRY

NBS benzoic acid (sample 39i) was used for calibration of the combustion bomb calorimeter; its specific energy of combustion is $-(26434.0 \pm 3.0) \mathrm{J} \cdot \mathrm{g}^{-1}$ under certificate conditions. Conversion to standard states(33) gives $-(26413.7 \pm 3.0) \mathrm{J} \cdot \mathrm{g}^{-1}$ for $\Delta_{c} \cup_{m}^{0} / M$, the specific energy of the idealized combustion reaction. Calibration experiments were interspersed with the 1,2,3,4-tetrahydro-9-methylcarbazole measurements. Nitrogen oxides were not formed in the calibration experime:its due to the high purity of the oxygen used and preliminary bomb flushing. The energy equivalent of the calorimeter obtained for the calibration series, $\varepsilon$ (calor), was

All tables are given at the end of this report. 


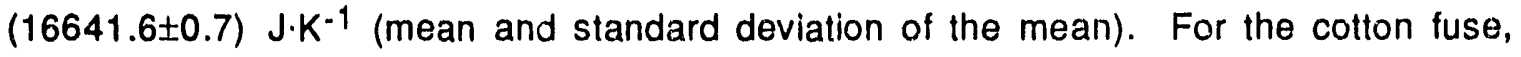
empirical formula $\mathrm{CH}_{1.774} \mathrm{O}_{0.887,} \Delta_{\mathrm{c}} \mathrm{U}_{\mathrm{m}}^{0} / \mathrm{M}$ was $-16945 \mathrm{~J} \cdot \mathrm{g}^{-1}$.

1,2,3,4-Tetrahydro-9-methylcarbazole was burned in the form of pellets. For each experiment $1.0 \times 10^{-3} \mathrm{dm}^{3}$ of water was added to the bomb, and the bomb was flushed and charged to $3.04 \mathrm{MPa}$ with pure oxygen. Judicious choice of sample and auxiliary masses allowed the temperature rise in each combustion series and its corresponding calibration series to be the same within 0.1 per cent. All experiments were completed within $0.01 \mathrm{~K}$ of $298.15 \mathrm{~K}$.

Auxiliary information, necessary for reducing apparent masses to masses, converting the energy of the actual bomb process to that of the isothermal process, and reducing to standard states, ${ }^{(33)}$ included a density at $298.15 \mathrm{~K} \mathrm{of} 1120 \mathrm{~kg} \cdot \mathrm{m}^{-3}$ and an estimated value of $5 \times 10^{-7} \mathrm{~m}^{3} \cdot \mathrm{K}-1$ for $\left(\partial \mathrm{V}_{\mathrm{m}} / \partial \mathrm{T}\right)_{\mathrm{p}}$ for 1,2,3,4-tetrahydro-9methylcarbazole. The density was obtained by weighing a pellet of known volume. The molar heat capacity at $298.15 \mathrm{~K}$ for 1,2,3,4-tetrahydro-9-methylcarbazole used in the corrections to standard states is given as part of the heat-capacity study results later in this report.

Nitric acid formed during the 1,2,3,4-tetrahydro-9-methylcarbazole combustions was determined by titration with standard sodium hydroxide. (34) Carbon dioxide was also recovered from the combustion products of each experiment. Anhydrous lithium hydroxide was used as absorbent.(16) The combustion products were checked for unburned carbon and other products of incomplete combustion, but none were detected. Carbon dioxide percentage recoveries were 100.001 0.009 (mean and standard ditviation of the mean) for the calibrations and $99.995 \pm 0.015$ for the corresponding 1,2,2,4-tetrahydro-9-methylcarbazole combustions.

A typical combustion experiment for 1,2,3,4-tetrahydro-9-methylcarbazole is summarized in table 2. It is impractical to list summaries for each combustion, but values of $\Delta_{\mathrm{c}} \cup_{\mathrm{m}}^{0} / \mathrm{M}$ for all the experiments are reported in table 3 . All values of $\Delta_{c} U_{m}^{O} / M$ in table 3 refer to the reaction:

$$
\mathrm{C}_{13} \mathrm{H}_{15} \mathrm{~N}(\mathrm{cr})+16.75 \mathrm{O}_{2}(\mathrm{~g})=13 \mathrm{CO}_{2}(\mathrm{~g})+7.5 \mathrm{H}_{2} \mathrm{O}(\mathrm{l})+0.5 \mathrm{~N}_{2}(\mathrm{~g}) \text {. }
$$

Table 3 also gives derived values of the standard molar energy of combustion $\Delta_{c} U_{m}^{0}$, the standard molar enthalpy of combustion $\Delta_{c} H_{m}^{O}$, and the standard molar enthalpy of formation $\Delta_{\mathrm{f}} \mathrm{H}_{\mathrm{m}}^{\mathrm{O}}$ for 1,2,3,4-tetrahydro-9-methylcarbazole. Values of $\Delta_{\mathrm{c}} \cup_{\mathrm{m}}^{\mathrm{O}}$ and $\Delta_{\mathrm{c}} \mathrm{H}_{\mathrm{m}}^{\circ}$ refer to reaction 3. The values of $\Delta_{\mathrm{f}} \mathrm{H}_{\mathrm{m}}^{0}$ refer to reaction 4:

$$
13 \mathrm{C}(\mathrm{cr} \text {, graphite })+7.5 \mathrm{H}_{2}(\mathrm{~g})+0.5 \mathrm{~N}_{2}(\mathrm{~g})=\mathrm{C}_{13} \mathrm{H}_{15} \mathrm{~N}(\mathrm{cr}) \text {. }
$$


Uncertainties given in table 3 are the "uncertainty interval" defined in reference 35. The enthalpies of formation of $\mathrm{CO}_{2}(\mathrm{~g})$ and $\mathrm{H}_{2} \mathrm{O}(\mathrm{I})$ were taken to be $-(393.51 \pm 0.13)$ and $-(285.830 \pm 0.042) \mathrm{kJ} \cdot \mathrm{mol}^{-1}$, respectively, as assigned by CODATA.(36)

\section{DENSITY MEASUREMENTS}

Measured derisities for 1,2,3,4-tetrahydro-9-methylcarbazole in the liquid phase (temperature range $348 \mathrm{~K}$ to $424 \mathrm{~K}$ ) are listed in table 4 . The temperatures are accurate to $0.001 \mathrm{~K}$. The densitometer cell manufacturer claims that the accuracy of densities measured with the cell ranges from $0.1 \mathrm{~kg} \cdot \mathrm{m}^{-3}$ for densities within $\pm 50 n \mathrm{~kg} \cdot \mathrm{m}^{-3}$ of the standard to $0.01 \mathrm{~kg} \cdot \mathrm{m}^{-3}$ for densities within $\pm 100 \mathrm{~kg} \cdot \mathrm{m}^{-3}$ of the standard. With the exception of $\mathrm{H}_{2} \mathrm{O}$ and possibly $\mathrm{D}_{2} \mathrm{O}$, densities of fluids are not known with sufficient accuracy above $373 \mathrm{~K}$ to justify the claimed uncertainties. Water was used as the standard for all measurements. The difference in density between water and 1,2,3,4-tetrahydro-9-methylcarbazole ranged from $61 \mathrm{~kg} \cdot \mathrm{m}^{-3}$ at $347.9 \mathrm{~K}$ to $66 \mathrm{~kg} \cdot \mathrm{m}^{-3}$ at $423.7 \mathrm{~K}$. Therefore, the expected accuracy of the 1,2,3,4-tetrahydro9 -methylcarbazole densities is $0.01 \mathrm{~kg} \cdot \mathrm{m}^{-3}$.

\section{VAPOR-PRESSURE MEASUREMENTS}

Vapor pressures for 9-methylcarbazole and 1,2,3,4-tetrahydro-9-methylcarbazole are reported in table 5. Following previous practice, $(25)$ the results obtained in the ebulliometric measurements were adjusted to common pressures. The common pressures, the condensation temperatures, and the difference between condensation and Loiling temperatures $\Delta T$ for the samples are reported. For both 9-methylcarbazole and 1,2,3,4-tetrahydro-9-methylcarbazole the small differences between the boiling and condensation temperatures (column 6 table 5) indicated correct operation of the equipment and the high purity of the samples. At the highest temperatures measured for each sample, the large increase in $\Delta T$ relative to that for the previous temperature is indicative of sample decomposition.

Cox Equation Fits to Vapor Pressures. The Cox equation(37) in the form:

$$
\ln \left(\mathrm{p} / \mathrm{p}_{\mathrm{ref}}\right)=\left\{1-\left(T_{\mathrm{ref}} / \mathrm{T}\right)\right\} \exp \left\{\mathrm{A}+\mathrm{B}(\mathrm{T} / \mathrm{K})+\mathrm{C}(\mathrm{T} / \mathrm{K})^{2}\right\}
$$

was fitted to the experimental vapor pressures with fixed pref and Tref values listed in table 6 . The values of $p_{r e f}$ and $T_{r e f}$ used were the respective $p_{c}$ and $T_{c}$ obtained in the simultaneous fittings of the vapor pressures and the d.s.c. two-phase heat capacities discussed later in this report. The vapor-pressure fitting procedure has been 
described. $(23,26)$ Parameters derived from the fits are given in table 6 . Details of the Cox equation fits are given in table 5 .

Derived Enthalpies of Vaporization. Enthalpies of vaporization $\Delta_{1}^{g} H_{m}$ were derived from the Cox equation fits by means of the Clapeyron equation:

$$
\mathrm{dp} / \mathrm{dT}=\Delta_{\uparrow}^{g} H_{m} /\left(T \Delta_{\uparrow}^{g} V_{m}\right) \text {. }
$$

$\Delta_{1}^{g} V_{m}$ is the increase in molar volume from the liquid to the real vapor. The Cox equation fits were employed to derive $\mathrm{dp} / \mathrm{dT}$. Estimates of liquid-phase volumes were made with the extended corresponding-states equation of Riedel, $(38)$ as formulated by Hales and Townsend:(39)

$$
\left(\rho / \rho_{c}\right)=1.0+0.85\left\{1.0-\left(T / T_{c}\right)\right\}+(1.692+0.986 \omega)\left\{1.0-\left(T / T_{c}\right)\right\}^{1 / 3^{\prime}}
$$

with $\rho_{C}=317 \mathrm{~kg} \cdot \mathrm{m}^{-3}, T_{C}=890 \mathrm{~K}$, and an acentric factor $\omega=0.473$ for 9 -methylcarbazole. For 1,2,3,4-tetrahydro-9-methylcarbazole, values of $\rho_{\mathrm{C}}=309 \mathrm{~kg} \cdot \mathrm{m}^{-3}$, $T_{C}=854 \mathrm{~K}$, and an acentric factor $\omega=0.521$ were used. [The acentric factor is defined as $\left\{-\lg \left(p / p_{c}\right)-1\right\}$, where $p$ is the vapor pressure at $T_{r}=0.7$ and $p_{c}$ is the critical pressure.] The Cox equation coefficients given in table 6 were used to calculate $p$. The critical densities were estimates. The uncertainty in the liquid-phase volumes was estimated to be 3 per cent. [For 1,2,3,4-tetrahydro-9-methylcarbazole in the temperature range $347 \mathrm{~K}$ tc $424 \mathrm{~K}$, a comparison of values calculated using equation (7) with the densities measured experimentally is given in column 3 of table 4 . The agreement is excellent.] Vapor-phase volumes were calculated with the virial equation of state truncated at the ihird virial coefficient. Second virial coefficients were estimated with the corresponding-states equation of Pitzer and Curl, (40) and third virial coefficients were estimated with the corresponding-states method of Orbey and Vera. (41) This formulation for third virial coefficients was applied successfully in analyses of the thermodynamic properties of benzene, toluene, and decane.(42) Third virial coefficients are required for accurate calculation of the gas volume for pressures greater than 1 bar. Uncertainties in the virial coefficients are assumed to be 10 per cent. Derived enthalpies of vaporization are reported in table 6 . For $p>1$ bar the uncertainties in the virial coefficients are the dominant contributions to the uncertainties in the derived enthalpies of vaporization. 
ADIABATIC HEAT-CAPACITY CALORIMETRY

Crystallization and Melting Studies. Crystallization of 1,2,3,4-tetrahydro-9methylcarbazole was initiated by slowly cooling (approximately $2.5 \mathrm{mK} \cdot \mathrm{s}^{-1}$ ) the liquid sample roughly $5 \mathrm{~K}$ below the triple-point temperature. Complete crystallization was ensured by maintaining the sample under adiabatic conditions in the partially melted state (10 to 20 per cent liquid) for approximately $8 \mathrm{~h}$. No spontaneous warming, which would indicate incomplete crystallization, was observed in this time period. The sample was cooled at an effective rate of $2 \mathrm{mK} \cdot \mathrm{s}^{-1}$ to crystallize the remaining liquild. Finally, the sample was thermally cycled from $<100 \mathrm{~K}$ to within $2 \mathrm{~K}$ of the triple-point temperature, where it was held for a minimum of $6 \mathrm{~h}$ to provide further tempering. All of the solid-phase measurements were performed upon crystals pre-treated in this manner.

The triple-point temperature $T_{t p}$ and sample purity were determined by measurement of the equilibrium melting temperatures $T(F)$ as a function of fraction $F$ of the sample in the liquid state.(43) Equilibrium melting temperatures were determined by measuring temperatures at approximately 300-s intervals for 0.8 to $1.2 \mathrm{~h}$ after an energy input and extrapolating to infinite time by assuming an exponential decay toward the equilibrium value. The observed temperatures at $1 \mathrm{~h}$ after an energy input were invariably within $3 \mathrm{mK}$ of the calculated equilibrium temperatures for $F$ values listed in table 8. The results indicated the presence of solid-soluble impurities, and published procedures $(44)$ were used to derive the apparent mole fraction of impurities, triple-point temperature, and effective distribution coefficient for the impurities between the two phases. The results are summarized in table 8 .

Phase Transformations and Enthalpy Measurements. Experimental molar enthalpy results are summarized in table 9 . The table includes both phase-transition enthalpies and single-phase measurements, which serve as checks on the integration of the heatcapacity results. Corrections for pre-melting caused by impurities were made in these evaluations. Results with the same series number in tables 9 and 10 were taken without interruption of adiabatic conditions.

Excellent reproducibility (within \pm 0.02 per cent) was obtained in the enthalpyof-fusion results. This inplies that phase $\mathrm{cr}(I)$ was formed reproducibly by means of the tempering methods described above. The sample showed four solid phases with a lambda transition near $210.4 \mathrm{~K}$, a first-order transition near $162.4 \mathrm{~K}$, and a heatcapacity "step" near $103.8 \mathrm{~K}$. The complete heat-capacity curve is shown in figure 5 . 
Conversion of phase $\operatorname{cr}(I)$ to phase $\operatorname{cr}(I 1)$ was achieved easily by cooling. Excellent reproducibility was obtained in the enthalpy-of-transition results. Details of measurements made and subsequently derived heat-capacity for the $\operatorname{cr}(11)$-to-cr(I) phase-change region are shown in figure 6 . The heat-capacity curve shown in this and other figures is consistent with the measurement results. The shape of the curve is not defined uniquely very near $T_{\text {trs }}$ for each transformation. However, this uncertainty does not have a significant effect on the uncertainty of the derived thermodynamic functions.

Conversion of phase $\mathrm{cr}($ II) to phase $\mathrm{cr}$ (III) required approximately $3 d$ of annealing near $160 \mathrm{~K}$. Prior to measurements of the transition enthalpy, the sample was annealed between $158 \mathrm{~K}$ and $162 \mathrm{~K}$ for 80,160 , and $240 \mathrm{~h}$ for series 8,9 , and 20, respectively. An estimate of $T_{t r s}$ was obtained as part of the series-20 measurements by adding sufficient energy to convert 85 per cent of the sample from phase $\operatorname{cr}$ (III) to phase $\operatorname{cr}($ II) and allowing the sample to approach equilibrium over a period of 2 days. At the end of this period the sample had not equilibrated completely, but an estimate of $T_{\text {trs }},(162.4 \pm 0.2) \mathrm{K}$, could be made. The uncertainty in $T_{\text {trs }}$ has no significant effect on the precision of the derived thermodynamic functions. Details of measurements made in the $\operatorname{cr}($ III)-to- $\operatorname{cr}($ II) phase-change region are shown in figure 7 .

Conversion of phase $\mathrm{cr}$ (III) to phase $\mathrm{cr}$ (IV) required approximately $2 \mathrm{~d}$ of annealing near $103 \mathrm{~K}$. Prior to measurements of the transition enthalpy, the sample was annealed between $100 \mathrm{~K}$ and $103 \mathrm{~K}$ for 45,80 , and $60 \mathrm{~h}$ for series 14,19 , and 20, respectively. The sample was annealed for $1 \mathrm{~h}$ only for series 11 and 12 , which accounts for the low transition enthalpies measured for these series. Detalls of measurements made in the $\mathrm{cr}$ (IV)-to-cr(III) phase-change region are shown in figure 8.

Heat Capacity Measurements. The experimental molar heat capacities under vapor saturation pressure $\mathrm{C}_{\mathrm{sat}, \mathrm{m}}$ determined by adiabatic calorimetry are listed in table 10 . Values in table 10 were corrected for effects of sample vaporization into the gas space of the calorimeter. The temperature increments were small enough to obviate the need for corrections for non-linear variation of $\mathrm{C}_{\mathrm{sat}, \mathrm{m}}$ with temperature except near the solidphase transition temperature. The precision of the heat-capacity measurements ranged from approximately 5 per cent at $5 \mathrm{~K}$, to 2 per cent at $11 \mathrm{~K}, 0.2$ per cent near $20 \mathrm{~K}$, and improved gradually to less than 0.1 per cent above $100 \mathrm{~K}$, except in the solid phase near the triple-point and solid-phase transition temperatures where equilibration times were long. The heat capacities for the crystal-phase in table 10 have not been 


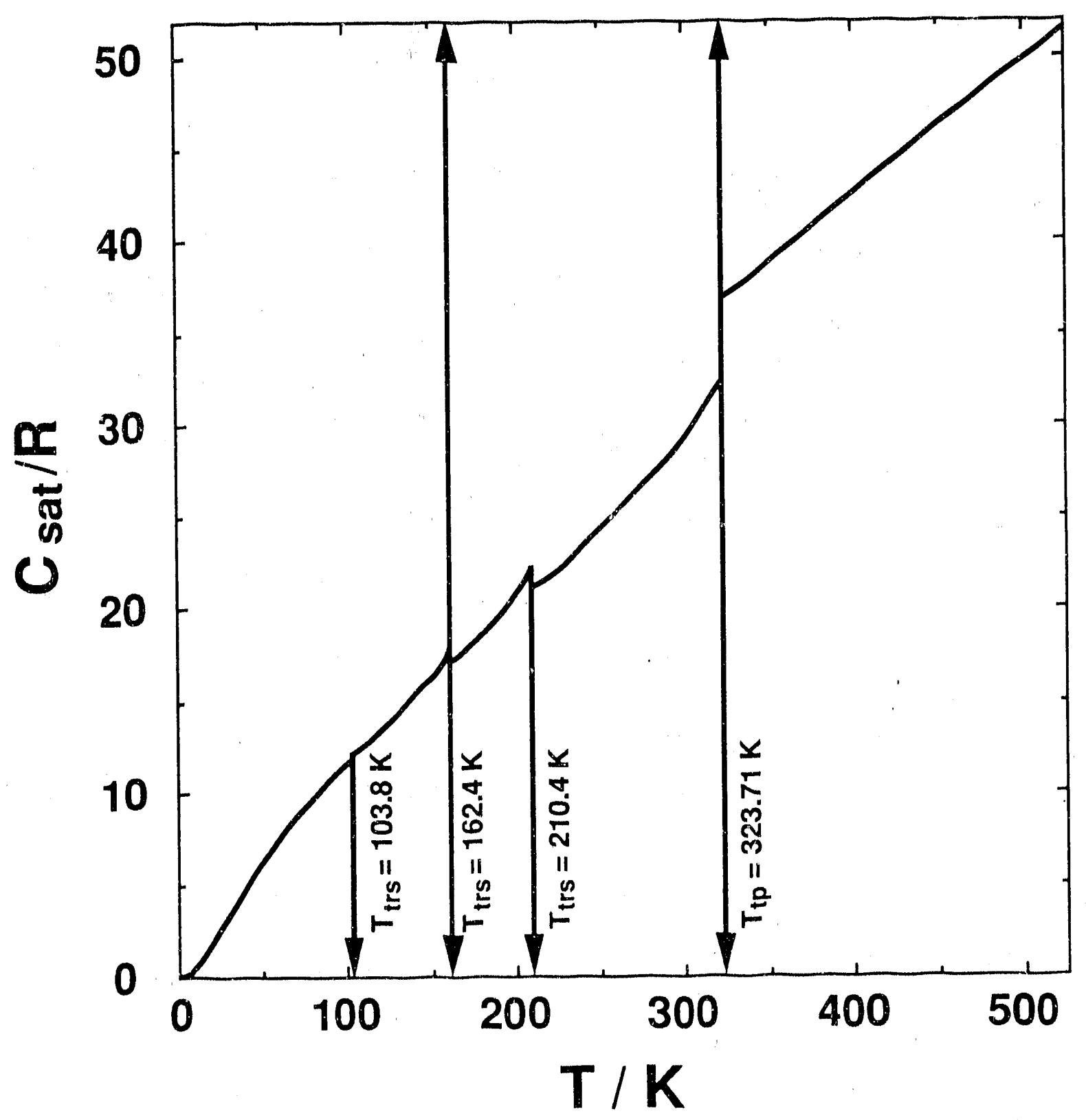

FIGURE5. Heat capacity against temperature for 1,2,3,4-tetrahydro-9-methylcarbazole. The vertical lines indicate phase-transition temperatures. The, upward-pointing arrows indicate first-order phase transitions. 


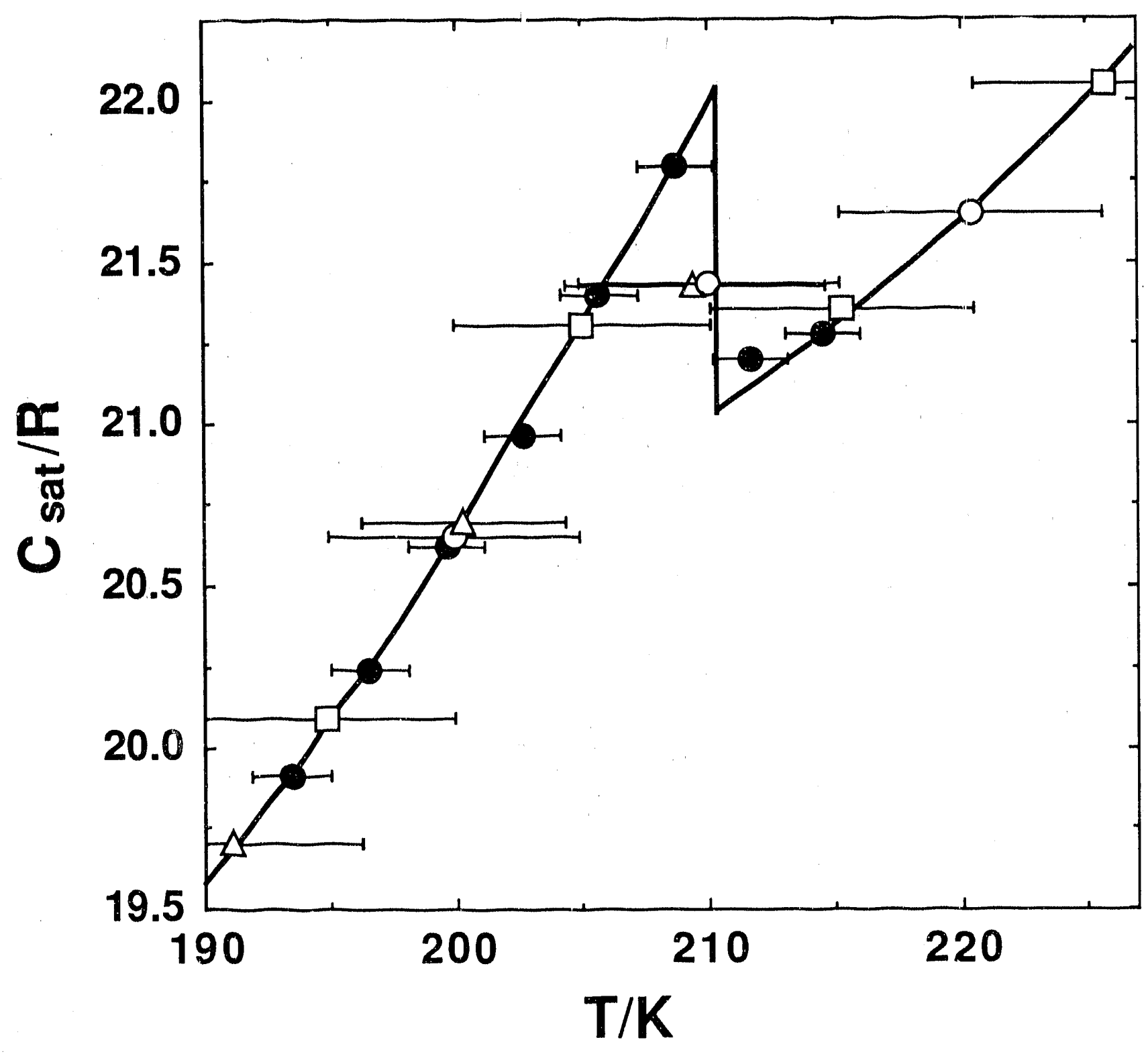

FIGURE 6. Average heat capacities in the $\operatorname{cr}(11)$-to- $\operatorname{cr}(1)$ transition region for $1,2,3,4$ tetrahydro-9-methylcarbazole. $\square$, series $3 ; 0$, series $6 ; 0$, series 7 ; $\triangle$, series 20 . 


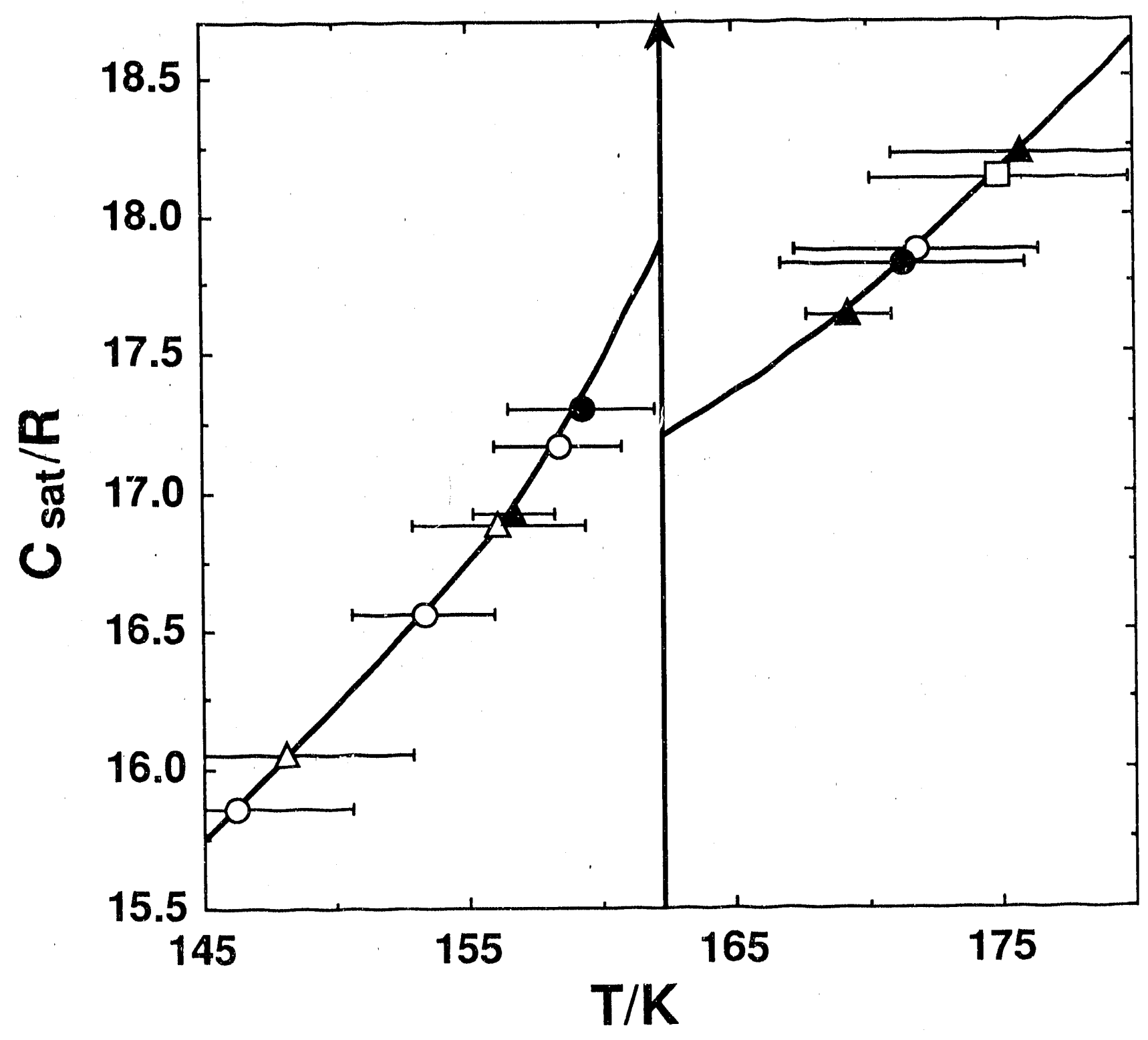

FIGURE 7. Average heat capacities in the $\operatorname{cr}(I I I)-10-\operatorname{cr}(11)$ transition region for 1,2,3,4tetrahydro-9-methylcarbazole. $\square$, Series $3 ; \boldsymbol{\Delta}$, series $8 ; 0$, series 9 ; $\Delta$, series $13 ; 0$, series 20 . Results of measurements spanning $T_{\text {trs }}$ (series 8 , series 9 , and series 20) are not shown. These are listed in table 9. The horizontal bars span the temperature increment associated with each average heat-capacity value. The heat-capacity curve is not defined uniquely between $162 \mathrm{~K}$ and $167 \mathrm{~K}$. See text. 


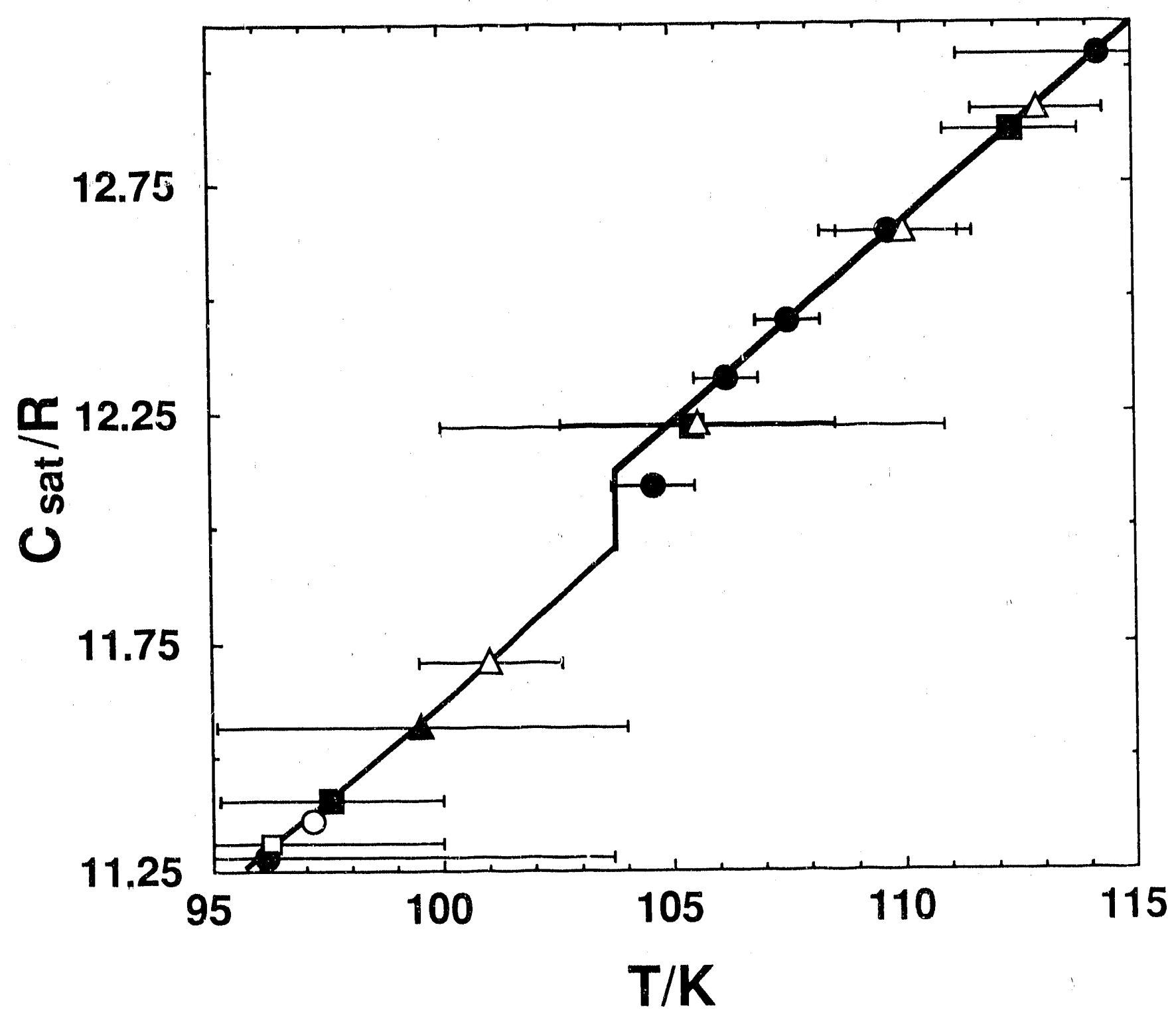

FIGURE 8. Average heat capacities in the $\operatorname{cr}(I V)$-to-cr(III) transition region for 1,2,3,4tetrahydro-9-methylcarbazole. $\mathbf{A}$, Series $11 ; 0$, series $12 ; \Delta$, series $14 ;$ $\square$, series $18 ; \mathbf{D}$, series $19 ; 0$, series 20 . Results of measurements spanning $T_{\text {trs }}$ for series 11 and series 12 are not shown, but are included in table 10. These were not included in the calculation of the transition enthalpy. The horizontal bars span the temperature increment associated with each average heat-capacity value. The heatcapacity curve is not defined uniquely between $103 \mathrm{~K}$ and $105 \mathrm{~K}$. See text. 
corrected for pre-melting. Pre-melting corrections(43) can be calculated with the temperature increments provided.

For heat-capacity measurements in the liquid phase, equilibrium was reached in less than $1 \mathrm{~h}$. Equilibration times for phase $\mathrm{cr}(\mathrm{IV})$ were less than $1 \mathrm{~h}$ for all temperatures below $103 \mathrm{~K}$. Equilibration times in the vicinity of the cr(IV)-tocr(III) transition temperature (roughly $103 \mathrm{~K}$ to $106 \mathrm{~K}$ ) were approximately $12 \mathrm{~h}$. For phase cr(III), equilibration times were less than $1 \mathrm{~h}$ between $106 \mathrm{~K}$ and $150 \mathrm{~K}$, and increased to $2 \mathrm{~h}$ at $155 \mathrm{~K}, 12 \mathrm{~h}$ at $160 \mathrm{~K}$, and $>48 \mathrm{~h}$ at $164 \mathrm{~K}$. For phase $\mathrm{cr}(\mathrm{Ii})$, equilibration times were less than $1 \mathrm{~h}$ for all temperatures. Equilibration times for phase $\operatorname{cr}(\mathrm{l})$ were less than $1 \mathrm{~h}$ fcr all temperatures less than $290 \mathrm{~K}$, and increased to $2 \mathrm{~h}$ at $300 \mathrm{~K}, 5 \mathrm{~h}$ at $320 \mathrm{~K}$. Extrapolation of the heat-capacity results to $T \rightarrow 0$ was made by linear extrapolation of a plot of $C_{s a t, m} / T$ against temperature squared for results below $10 \mathrm{~K}$.

\section{DIFFERENTIAL SCANNING CALORIMETRY}

Theoretical Background. The theoretical background for the determination of heat capacities for the liquid phase at vapor-saturation pressure $C_{s a t, m}$ with results obtained with a d.s.c. has been described.(31,45) If two phases are present and the liquid is a pure substance, then the vapor pressure $p$ and the chemical potential $\mu$ are Independent of the amount of substance $n$ and the cell volume $V_{x}$, and are equal to $p_{s a t}$ and $\mu_{\text {sat. }}$. The two-phase heat capacities at cell volume $V_{x}, C_{x, m}$, can be expressed in terms of the temperature derivatives of these quantities:

$$
n C_{x, m}^{l l} / T=-n\left(\partial^{2} \mu / \partial T^{2}\right)_{s a t}+V_{x}\left(\partial^{2} p / \partial T^{2}\right)_{s a t}+\left(\partial V_{x} / \partial T\right)_{x}(\partial p / \partial T)_{\text {sat }} .
$$

The third term on the right-hand side of equation (8) includes the thermal expansion of the cell. In this research the thermal expansion of the cells was expressed as:

$$
V_{x}(T) / V_{x}(298.15 K)=1+a y+b y^{2} \text {, }
$$

where, $y=(T-298.15) \mathrm{K}, \mathrm{a}=3.216 \times 10^{-5} \mathrm{~K}^{-1}$, and $\mathrm{b}=5.4 \times 10^{-8} \mathrm{~K}^{-2}$.

Values of $(\partial \mathrm{p} / \partial \mathrm{T})_{\text {sat }}$ can be calculated based on the vapor pressures measured in this research. Therefore, with a minimum of two different filling levels of the cell, $\left(\partial^{2} \mathrm{p} / \partial \mathrm{T}^{2}\right)_{\text {sat }}$ and $\left(\partial^{2} \mu / \partial T^{2}\right)$ sat can be determined. In this research three fillings were

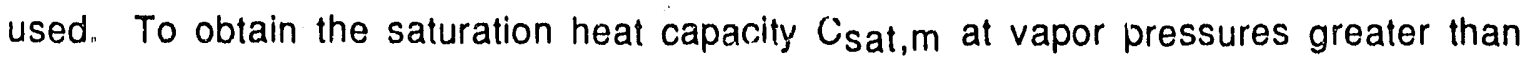
$0.1 \mathrm{MPa}$, the limit where the cell is full of liquid is required; i.e., $\left(n / V_{x}\right)=\left\{1 / V_{m}(1)\right\}$ where $V_{m}(I)$ is the molar volume of the liquid: 


$$
\lim _{\left(n / V_{x}\right) \rightarrow\left\{1 / N_{m}(1)\right\}}\left(n C_{v, m}^{\prime \prime} / T\right)=V_{m}(1)\left(\partial^{2} p / \partial T^{2}\right)_{s a t}-n\left(\partial^{2} \mu / \partial T^{2}\right)_{s a t}
$$

$\mathrm{C}_{\text {sat, }} \mathrm{m}$ is obtained from the expression:

$$
\lim _{\left(n N_{x}\right) \rightarrow\left\{1 / N_{m}(1)\right\}}\left(n C_{v, m}^{\prime \prime}\right)=n\left[C_{s a t, m}-\left\{T(\partial p / \partial T)_{s a t}\left(d V_{m}(I) / d T\right)\right\}\right]
$$

Thus, reliable liquid-density values are also required to determine $C_{s a t, m}$.

Table 11 lists the experimental two-phase heat capacities $C_{x, m}^{11}$ for 9-methylcarbazole and 1,2,3,4-tetrahydro-9-methylcarbazole obtained for three cell fillings for each compound. Heat capacities were determined at $20-\mathrm{K}$ intervals with a heating rate of $0.083 \mathrm{~K} \cdot \mathrm{s}^{-1}$ and a 120 -s equilibration period between heats. Sample decomposition precluded heat-capacity measurements above $760 \mathrm{~K}$ for 9-methylcarbazole and $660 \mathrm{~K}$ for 1,2,3,4-tetrahydro-9-methylcarbazole.

For other compounds, e.g., 2-aminobiphenyl(7) and dibenzothiophene, ${ }^{(46)}$ a rapid heating method was used for critical temperature and critical density determinations. By elıploying a single continuous heat at a rate of $0.333 \mathrm{~K} \cdot \mathrm{s}^{-1}$, sample decomposition was greatly reduced, and the abrupt decrease in heat capacity associated with the conversion from two phases to one phase was observed. However, this method failed in the present research as there was extensive sample decomposition above the range of the heat-capacity measurements.

For both 9-methylcarbazole and 1,2,3,4-tetrahydro-9-methylcarbazole values for $T_{c}$ and $p_{c}$ were estimated by a simultaneous non-linear least-squares fit of the vapor pressures listed in table 5 and the $C_{x, m}^{\prime l}$ values given in table 11. $C_{s a t, m}$ values were derived from results of the fit and equation (11). Experimental $C_{x, m}^{\prime l}$ values were converted to $C_{v, m}^{\| l}$ by means of equation (9) for the cell expansion and the vaporpressure fit described below for $(\partial \mathrm{p} / \partial \mathrm{T})_{\text {sat }}$.

$$
C_{v, m}^{\prime \prime}=C_{x, m}^{\prime \prime}-T / n\left\{\left(\partial V_{x} / \partial T\right)_{x}(\partial p / \partial T)_{s a t}\right\} .
$$

The values of $C_{v, m}^{\prime \prime}$ were used to derive functions for $\left(\partial^{2} p / \partial T^{2}\right)_{\text {sat }}$ and $\left(\partial^{2} \mu / \partial T^{2}\right)$ sat. The Cox equation $(37)$ was used to represent the vapor pressures in the form:

$$
\ln \left(p / p_{c}\right)=\left(1-1 / T_{r}\right) \exp \left(A+B T_{r}+C T_{r}^{2}\right)
$$

with $T_{r}=T / T_{c}$, where $T_{c}$ and $p_{c}$ are the critical temperature and critical pressure. Both the $T_{c}$ and $p_{c}$ were included as variables in the non-linear least-squares analysis. The 
functional form chosen for variation of the second derivative of the chemical potential with temperature was:

$$
\left(\partial^{2} \mu / \partial T^{2}\right)_{s a t} /\left(J \cdot K^{-2} \cdot \mathrm{mol}^{-1}\right)=\sum_{i=0}^{n} b_{i}\left(1-T / T_{c}\right)^{i}
$$

\{For compounds where sufficient information was available to evaluate reliably $\left(\partial^{2} \mu / \partial T^{2}\right)$ sat (e.g., benzene(47)), four terms (i.e, expansion to $n=3$ ) were required to represent the function. Thus, four terms were used in this research.\} In these fits the sum of the weighted squares in the following function was minimized:

$$
\Delta=C_{v, m}^{l l} / R-\left\{V_{m}(i) T / n R\right\}\left(\partial^{2} p / \partial T^{2}\right)_{s a t}+(T / R)\left(\partial^{2} \mu / \partial T^{2}\right)_{s a t} .
$$

For the vapor-pressure fits, the functional forms of the weighting factors used have been reported. $(23,26)$ Within the heat-capacity results, the weighting factors were proportional to the square of the mass of sample used in the measurements. Table 12 lists the coefficients datermined in the non-linear least-squares fit. A weighting factor of 20 was used to increase the relative weights of the vapor-pressure measurements in the fit. The weighting factor reflects the higher precision of the vapor-pressure values relative to the experimental heat capacities.

Values of $\mathrm{C}_{\text {sat, }} \mathrm{m}$ for 9-methylcarbazole and 1,2,3,4-tetrahydro-9methylcarbazole were derived from $C_{v, m}^{\prime \prime}\left(\rho=\rho_{s a t}\right)$ with densities obtained using equation (7) (see Derived Enthalpies of Vaporization section). The results for $C_{v, m}^{\prime l}\left(\rho=\rho_{\text {sail }} / R\right.$ and $C_{s a t, m} / R$ are reported in table 13 . The estimated uncertainty in these values is 1 per cent. Differences between $C_{v, m}^{\prime \prime}\left(\rho=\rho_{\text {sat }}\right) / R$ and $C_{s a t, m} / R$ are significant only at the highest temperatures measured. Differences in these quantities can be large as the critical temperature is approached.(45)

\section{THERMODYNAMIC PROPERTIES IN THE CONDENSED STATE}

Entropies and enthalpies under vapor saturation pressure relative to that of the crystals at $T \rightarrow 0$ for the solid and liquid phases of 1,2,3,4-tetrahydro-9-methylcarbazole and the liquid phase of 9-methylcarbazole are listed in table 14. (These functions were published previously $(9)$ for the crystai phase of 9-methylcarbazole.) The tabulated values were derived by integration of the smoothed heat capacities corrected for premelting, together with the entropies and enthaipies of transition and fusion. The heat capacities were smoothed with cubic-spline functions by least-squares fits to six points at a time and by requiring continuity in value, slope, and curvature at the junction of 
successive cubic functions. Due to limitations in the spline-function procedure, some acceptable values from tables 10 and 13 were not included in the fit, while in other regions graphical values were introduced to ensure that the second derivative of the heat capacity with respect to temperature was a smooth function of temperature. Premelting corrections were made for 1,2,3,4-tetrahydro-9-methylcarbazole by means of standard methods $(43)$ for solid-insoluble impurities and the mole-fraction impurities value shown in table 1.

\section{THERMODYNAMIC PROPERTIES IN THE IDEAL-GAS STATE}

Enthalpies and entropies at selected temperatures for the ideal gas were calculated using values in tables 7 and 14 and are listed in columns 2 and 4 of table 15. Entropies and enthalpies of compre sion to $101.325 \mathrm{kPa}$ were calculated based on the virial equation truncated after the third virial coefficient.

$$
p V_{m}=R T+B p+C p^{2}
$$

Formulations used to calculate the entropy and enthalpy of compression are:(48)

$$
\begin{gathered}
\Delta S_{\text {comp,m }}=R \ln (p)+(d B / d T) p+(d C / d T) p^{2}, \\
\Delta H_{c o m p, m}=\{B-T(d B / d T)\} p+\{C-T(d C / d T)\}\left(p^{2} / 2\right) .
\end{gathered}
$$

Equations (17) and (18) are derived from equations (16.21) and (16.27), respectively, of reference 48 . Temperature derivatives were estimated by numerical differentiation of virial coefficients estimated by the methods of Pitzer and Curl( 40$)$ and Orbey and Vera. ${ }^{(41)}$

The first term in equation (17) is the entropy of compression, if the gas were ideal. The uncertainty in this term is not significant. The sum of the second and third terms of equation (17) is the "gas-imperfection correction" to the entropy of compression. Equation (18) gives the "gas-imperfection correction" to the enthalpy of compression directly, as the ideal-gas value is zero. The gas-imperfection corrections are listed in table 15. Uncertainties in these values is difficult to assess because temperature derivatives of estimated vaiues are involved. An uncertainty of 10 per cent of the calculated correction was assumed.

The derived ideal-gas enthalpies and entropies for 1,2,3,4-tetrahydro-9methylcarbazole were combined with the condensed-phase enthalpy of formation given in table 3 to calculate the enthalpies, entropies, and Gibbs energies of formation listed in columns 6,7 , and 8 , respectively, of table 15 . 
The energy of combustion for the crystal phase of 9-methylcarbazole was reported by Good(10) and Jimenez et al. ${ }^{(49)}$ The value reported by Good $\Delta_{c} U_{m}^{0}=$ $-(6787.6 \pm 0.8) \mathrm{kJ} \cdot \mathrm{mol}^{-1}$ was revised slightly in this research to $\Delta_{\mathrm{c}} \mathrm{U}_{\mathrm{m}}^{\mathrm{O}}=$ $-(6786.6 \pm 0.8) \mathrm{kJ} \mathrm{mol}^{-1}$. In the revised calculation, the estimated density for the crystal phase of 9 -methylcarbazole employed by $\operatorname{Good}(10)$ was replaced by a more reliable value determined by $x$-ray crystallography. $(50)$ The value reported by Jimenez et al. (49) for the molar energy of combustion $-(6785.8 \pm 1.7) \mathrm{kJ} \mathrm{mol}^{-1}$ is in excellent agreement with that of Good.(10) The value for the molar enthalpy of formation $\Delta_{\mathrm{f}} \mathrm{H}_{\mathrm{m}}^{0}=$ $(104.1 \pm 1.0) \mathrm{kJ} \cdot \mathrm{mol}^{-1}$ employed here for the ideal-gas property calculations is derived from the average of the energy of combustion values.

Enthalpies and entropies for nitrogen and equilibrium hydrogen were determined from JANAF tables. (51) Values for graphite were determined with the polynomial(52) used to calculate the values from $298.15 \mathrm{~K}$ to $6000 \mathrm{~K}$ listed in the JANAF tables. All uncertainties in table 15 represent one standard deviation and do not includio uncertainties in the properties of the elements.

\section{CALCULATION OF SUBLIMATION PRESSURES}

The "third-law" method was employed to calculate sublimation pressures for 9-methylcarbazole from $298.15 \mathrm{~K}$ to the triple-point temperature. The "third-law" values were calculated from the tabulated thermodynamic functions of the ideal gas (table 15) and the crystalline solid (table 14). The method applied here was the same as that used previously for biphenyl.(45) The sublimation vapor pressures were represented by the equation:

$$
\ln \left(p / p_{0}\right)=31.97-1.0424 \times 10^{4}(T / K)^{-1}-1.5082 \times 10^{5}(T / K)^{-2} \text {. }
$$

in the temperature region 298.15 to $362.5 \mathrm{~K}$ with $\mathrm{p}_{\mathrm{O}}=1 \mathrm{~Pa}$.

\section{DISCUSSION}

\section{COMPARISON OF RESULTS WITH LTTERATURE}

The property-measurement results reported here for 1,2,3,4-tetrahydro-9methylcarbazole are the first for this. important intermediate in the carbazole $/ \mathrm{H}_{2}$ hydrodenitrogenation reaction network. A search of the literature (Chemical Abstracts; 1907 through 1990) failed to locate any previous thermodynamic-property measurements on this material. 
Jiménez et al.(49) reported sublimation pressures for 9-methylcarbazole determined by the Knudsen-effusion methou in addition to the energy of combustion discussed earlier. A comparison with those calculated with equation (19) is shown in figure 9. The values reported by Jiménez et al.(49) are between 5 per cent and 7 per cent lower than the calculated values. The agreement is excellent when the very low pressure range $(p<0.5 \mathrm{~Pa})$ is considered.

\section{SUMMARY and HI GHLIGHTS}

- Thermochemical and thermophysical properties for 9-methylcarbazole and 1,2,3,4-tetrahydro-9-methylcarbazole are reported. For 1,2,3,4tetrahydro-9-methylcarbazole, the properties measured included the energy of combustion, and vapor pressures, heat capacities, and densities over a range of temperatures. For 9-methylcarbazole, vapor pressures and heat capacities to high temperatures (to $750 \mathrm{~K}$ ) are reported.

- Ideal-gas thermodynamic properties for 9-methylcarbazole and 1,2,3,4tetrahydro-9-methylcarbazole were determined based on the accurate calorimetric measurements. The results for 9-methylcarbazole will be used to accurately estimate the properties of carbazole through the application of the methods of group additivity.

- Gibbs energies of formation for 9-methylcarbazole and 1,2,3,4-tetrahydro9-methylcarbazole for equilibria calculations were derived. The determination of these is an essential precursor to a thermodynamic analysis of the initial steps of the hydrogenolysis of carbazole, which will be presented in a subsequent topical report.

- Carbazole-type molecules are particularly difficult to remove in the HDN (hydrodenitrogenation) of process fluids derived from heavy petroleum. The results reported here will be used to provide an improved understanding of the underlying reasons for these difficulties, and can provide a guide to the development of more efficient process conditions than used presently. 


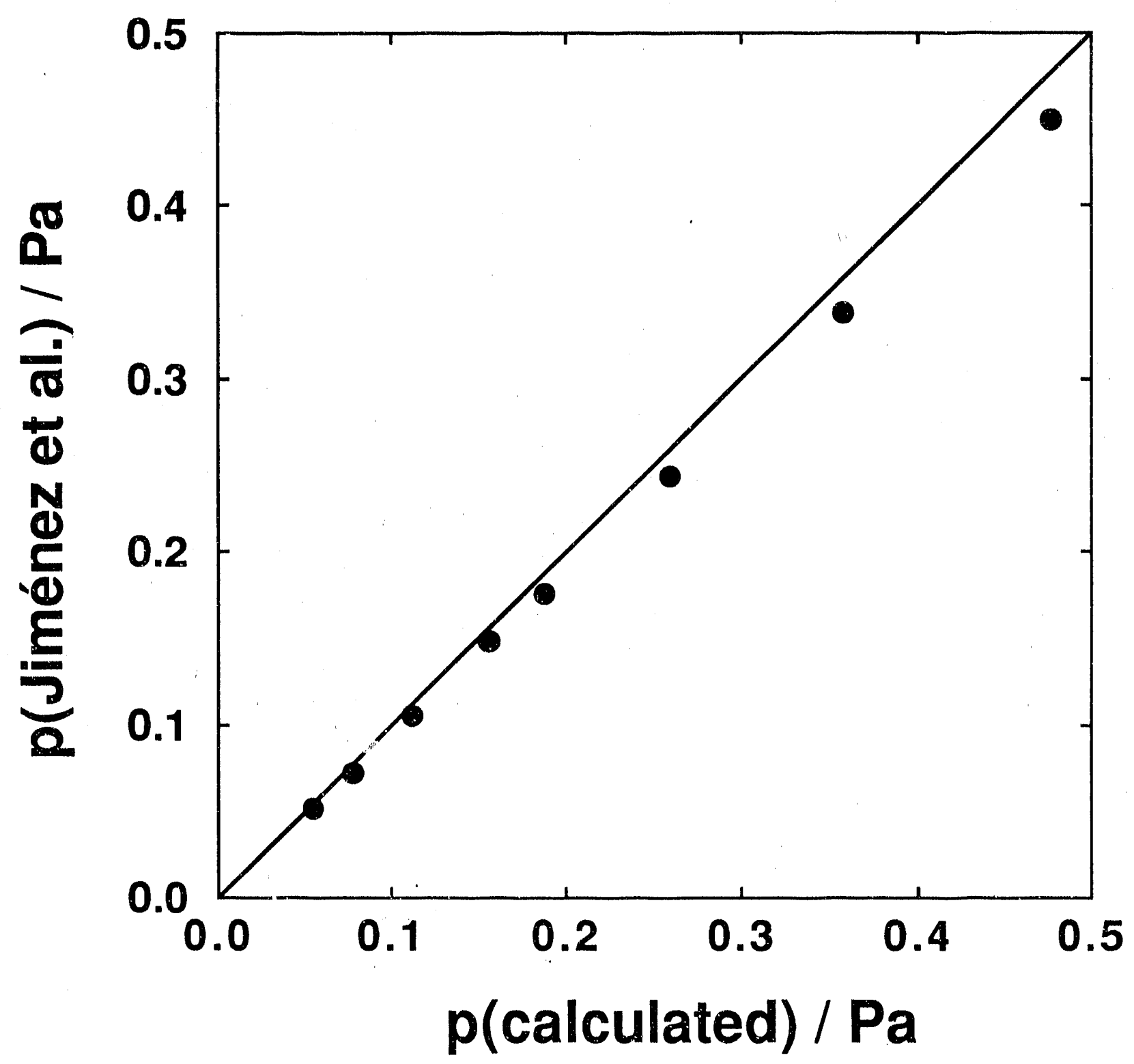

FIGURE 9. Parity plot comparing sublimation pressures measured by Jiménez et al.(49) with vaiues calculated using equation (19). The line corresponds to perfect agreement between the measured and calculated values. Jiménez et al.(49) 


\section{REFERENCES}

1. Steele, W. V.; Chirico, R. D.; Collier, W. B.; Harrison, R. H.; Gammon, B. E. Assessment of Thermodynamic Data and Needs, Including Their Economic Impact, for Development of New Fossil Fuel Refining Processes. NIPER-159. Published by DOE Fossil Energy, Bartlesville Project Otfice. Available from NTIS Report No. DE-86000298, June 1986.

2. Katzer, J. R.; Sivasubramanian, R. Catal. Rev.-Sci. Eng. 1979, 20, 155.

3. Ledorix, M. J. Catalysis (London) 1985, 7, 125.

4. Ho, T. C. Catal. Rev.-Sci. Eng. 1988, 30, 117.

5. Steele, W. V., and F. D. Chirico. Thermodynamics and the Hydrodenitrogenation of Indole. In three parts: Part I. Thermodynamic Properties of Indoline and 2-Methylindole, Part II. Gibbs Energies of Reaction in the Hydrodenitrogenation of Indole, Part III. Thermodynamic Equilibria and Comparison with Literature Kinetic Studies. NIPER-415. Published by DOE Fossil Energy, Bartlesville Project Office. Available from NTIS, Report No. DE-89000751, June 1989.

6. Steele, W. V.; Chirico, R. D. Thermodynamics of the Hydrodenitrogenation of Quinoline. NIPER-468. Published by DOE Fossil Energy, Bartlesville Project Office. Available from NTIS Report No. DE-90000245, June 1990.

7. Steele, W. V.; Chirico, R. D.; Knipmeyer, S. E.; Nguyen, A. The Thermodynamic Properties of 2-Aminobiphenyl. (An Intermediate in the Carbazole/Hydrogen Reaction Network) NIPER-482, December 1990. Published by DOE Fossil Energy, Bartlesville Project Office. Available from NTIS Report No. DE91002209.

8. Benson, S. W. Thermochemical Kinetics. 2nd edition. Wiley: New York, 1976.

9. Messerly, J. F.; Todd, S. S.; Finke, H. L.; Good, W. D.; Gammon, B. E. J. Chem. Thermodynamics 1988, 20, 209.

10. Good, W. D. J. Chem. Eng. Data 1972, 17, 28.

11. Commission on Atomic Weights and Isotopic Abundances. Pure Appl. Chem. 1 S333, $55,1101$.

12. Cohen, E. R.; Taylor, B. N. J. Phys. Chem. Ref. Data 1988, 17, 1795.

13. Metrologia 1969, 5, 35.

14. McCrackin, F. L.; Chang, S. S. Rev. Sci. Instrum. 1975, 46, 550.

15. Good, W. D.; Moore, R. T. J. Chem. Eng. Data 1970, 15, 150.

16. Good, W. D.; Smith, N. K. J. Chem. Eng. Data 1969, 14, 102.

17. Good, W. D. J. Chem. Eng. Data 1969, 14, 231.

18. Good, W. D.; Scott, D. W.; Waddington, G. J. Phys. Chem. 1956, 60, 1080.

19. Good, W. D.; Douslin, D. R.; Scott. D. W.; George, A.; Lacina, J. L.; McCullough, J.P.; Waddington, G. J. Phys. Chem. 1959, 63, 1133.

20. Smith, N. K.; Stewart, R. C., Jr.; Osborn, A. G.; Scott, D. W. J. Chem. Thermodynamics 1980, 12, 919.

21. Chirico, R. D.; Hossenlopp, I. A.; Nguyen, A.; Strube, M. M.; Steele, W. V. Thermodynamic Studies Related to the Hydrogenation of Phenanthrene. NIPER247. Published by DOE Fossil Energy, Bartlesville Project Office. Available from NTIS Report No. DE-87001252, April 1987.

22. Goldberg, R. N.; Nuttall, R. N.; Prosen, E. J.; Brunetli, A. P. NBS Report 10437, U. S. Department of Commerce, National Bureau of Standards, June 1971.

23. Steele, W. V.; Archer, D. G.; Chirico, R. D.; Collier, W. B.; Hossenlopp, I. A.; Nguyen, A.; Smith, N. K.; Gammon, B. E. J. Chem. Thermodynamics 1988, 20, 1233.

24. Swietoslawski, W. Ebulliometric Measurements. Reinhold: New York, 1945.

25. Osborn A. G.; Douslin, D. R. J. Chem. Eng. Data 1966, 11, 502.

26. Chirico, R. D.; Nguyen, A.; Steele, W. V.; Strube, M. M.; Tsonopoulos, C. J. Chem. Eng. Data 1989, 34, 149. 
27. Antoine, C. C. R. Acad. Sci. 1888, 107, 681.

28. Douslin, D. R.; McCullough, J.P. U. S. Bureau of Mines. Report of Investigation $6149,1963, \mathrm{pp} .11$.

29. Douslin, D. R.; Osborn A. G. J. Sci. Instrum. 1965, 42, 369.

30. Steele, W. V.; Chirico, R. D.; Knipmeyer, S. E.; Smith, N. K. High-Temperature Heat-Capacity Measurements and Critical Property Determinations using a Differential Scanning Calorimeter. (Development of Methodology and Application to Pure Organic Compounds) NIPER-360, December 1988. Published by DOE Fossil Energy, Bartlesville Project Office. Available from NTIS Report No. DE89000709.

31. Knipmeyer, S. E.; Archer, D. G.; Chirico, R. D.; Gammon, B. E.; Hossenlopp, I. A.; Nguyen, A.; Smith, N. K.; Steele, W. V.; Strube, M. M. Fluid Phase Equilibria $1989,52,185$.

32. Mraw, S. C.; Naas, D. F. J. Chem. Thermodynamics 1979, 11, 567.

33. Hubbard, W. N.; Scott, D. W.; Waddington, G. Experimental Thermochemistry. Rossini, F. D.: editor. Interscience: New York, 1956, Chapt. 5, pp. 75-128.

34. Smith, N. K.; Good, W. D. J. Chem. Eng. Data 1967, 12, 572.

35. Rossini, F. D. Experimental Thermochemistry. Rossini, F. D.: editor. Interscience: New York. 1956, Chapt. 14, pp. 297-320.

36. Cox, J. D.; Wagman, D. D.; Medvedev, V. A.: editors. CODATA Key Values for Thermodynamics. Hemisphere: New York. 1989.

37. Cox, E. R. Ind. Eng. Chem. 1936, 28, 613.

38. Riedel, L. Chem.-Ing.-Tech 1954, 26, 259.

39. Hales, J. L.; Townsend, R. J. Chem. Therrnodynamics 1972, 4, 763.

40. Pitzer, K. S.; Curl, R. F. Jr. J. Am. Chem. Soc. 1957, 79, 2369.

41. Orbey, H.; Vera, J. H. AlChE Journal, 1983, 29, 107.

42. Steele, W. V.; Chirico, R. D. To be submitted to Ind. Eng. Chem. Res.

43. Westrum, E. F., Jr.; Furukawa, G. T.; McCullough, J. P. Experimental Thermodynamics. Vol. 1. McCullough, J. P.; Scott, D. W.: editors. Butterworths: London. 1968, Chapt 5.

44. Mastrangelo, S. V. R.; Dornte, R. W. J. Am. Chem. Soc. 1955, 77, 6200.

45. Chirico, R. D.; Knipmeyer, S. E.; Nguyen, A.; Steele, W. V. J. Chem. Thermodynamics 1989, 21, 1307.

46. Chirico, R. D.; Knipmeyer, S. E.; Nguyen, A.; Steele, W. V. The Thermodynamic Properties of Dibenzothiophene. J. Chem. Thermodynamics In press 1991.

47. Goodwin, R. D. J. Phys. Chem. Ref. Data 1988, 17, 1541.

48. Lewis, G. N.; Randall, M. Thermodynamics. Revised by Pitzer, K. S.; Brewer, L. 2nd edition. McGraw-Hill: New York. 1961.

49. Jiménez, P.; Roux, M. V.; Turrión, C. J. Chem. Thermodynamics 1990, 22, 721.

50. Popova, E. G.; Chetkina, L. A. Zh. Strukt. Khim. 1979, 20, 665.

51. Chase, M. W., Jr.; Davies, C. A.; Cowney, J. R.; Frurip, D. J.; McDonald, R. A.; Syverud, A. N. JANAF Thermochemical Tables Third edition. Supplement to J. Phys. Chem. Ret. Data 1985, 14.

52. Chirico, R. D.; Archer, D. G.; Hossenlopp, I. A.; Nguyen, A.; Steele, W. V.; Gammon, B. E. J. Chem. Thermodynamics 1990, 22, 665 . 
TABLE 1. Calorimeter and sample characteristics for adiabatic heat-capacity calorimetry studies on 1,2,3,4-tetrahydro-9-methylcarbazole: $m$ is the sample mass; $V_{1}$ is the internal volume of the calorimeter; $T_{c a l}$ is the temperature of the calorimeter when sealed; $p_{c a l}$ is the pressure of the helium and sample when sealed; $r$ is the ratio of the heat capacity of the full calorimeter to that of the empty; $T_{\max }$ is the highest temperature of the measurements; and $\delta \mathrm{C} / \mathrm{C}$ is the vaporization correction; $x_{p r e}$ is the mole-fraction impurity used for pre-melting corrections.

\begin{tabular}{lc}
\hline $\mathrm{m} / \mathrm{g}$ & 45.828 \\
$\mathrm{~V}_{\mathrm{i}}(298.15 \mathrm{~K}) / \mathrm{cm}^{3}$ & 61.78 \\
$\mathrm{~T}_{\mathrm{cal}} / \mathrm{K}$ & 298.3 \\
$\mathrm{P}_{\mathrm{ca}} / \mathrm{kPa}$ & 7.83 \\
$\left.\mathrm{r}_{(} \mathrm{T}_{\max }\right)$ & 3.3 \\
$r_{\mathrm{m} / \mathrm{n}}$ & 1.8 \\
$10^{2}(\delta \mathrm{C} / \mathrm{C})_{\max }$ & 0.033 \\
$x_{p r e}$ & 0.00035 \\
\hline
\end{tabular}


TABLE 2. Typical combustion experiment at $298.15 \mathrm{~K}$ for 1,2,3,4-tetrahydro-9-methylcarbazole $\quad\left(p^{0}=101.325 \mathrm{kPa}\right)$ a

\begin{tabular}{|c|c|}
\hline$m^{\prime}($ compound $) / g$ & 0.910170 \\
\hline$m^{\prime \prime}($ fuse $\theta) / g$ & 0.001725 \\
\hline $\mathrm{n}_{i}\left(\mathrm{H}_{2} \mathrm{O}\right) / \mathrm{mol}$ & 0.05535 \\
\hline$m(P t) / g$ & 20.810 \\
\hline$\Delta T=\left(t_{1}-t_{f}+\Delta t_{\text {corr }}\right) / K$ & 2.14287 \\
\hline$\varepsilon($ calor $)(\Delta T) / J$ & -35660.8 \\
\hline$\varepsilon(\operatorname{con} t)(\Delta T) / J \quad b$ & -39.3 \\
\hline$\Delta U_{\operatorname{lgn}} / J$ & 0.8 \\
\hline$\Delta U_{\text {dec }}\left(\mathrm{HNO}_{3}\right) / \mathrm{J}$ & 35.3 \\
\hline$\Delta U$ (corr. to std. states)/J c & 18.7 \\
\hline$-m^{\prime \prime}\left(\Delta_{c} U_{m}^{0} / M\right)(f u s e) / J$ & 29.2 \\
\hline$m^{\prime}\left(\Delta_{c} U_{m}^{0} / M\right)($ compound $) / J$ & -35616.1 \\
\hline$\left(\Delta_{c} \cup_{m}^{0} / M\right)($ compound $) / J \cdot g^{-1}$ & -39131.3 \\
\hline
\end{tabular}

a The symbols and abbreviations of this table are those of reference 33 except as noted.

b $\varepsilon_{i}($ cont $)\left(t_{i}-298.15 K\right)+\varepsilon_{f}($ cont $)\left(298.15 K-t_{f}+\Delta t_{\text {corr }}\right)$.

c Items 81 to 85,87 to 90,93 , and 94 of the computational form of reference 33 .

TABLE 3. Summary of energies of combustion and molar thermochemical functions for 1,2,3,4-tetrahydro-9-methylcarbazole $\left(T=298.15 \mathrm{~K}\right.$ and $\left.\mathrm{p}^{\circ}=101.325 \mathrm{kPa}\right)$

$$
\begin{aligned}
& \left.\left\{\left(\Delta_{\mathrm{c}} U_{\mathrm{m}}^{0} / \mathrm{M}\right) \text { (compound }\right)\right\} /\left(\mathrm{J} \cdot \mathrm{g}^{-1}\right) \\
& \begin{array}{llllll}
-39131.3 & -39137.0 & -39131.2 & -39133.9 & -39133.8 & -39134.6
\end{array} \\
& <\left\{\left(\Delta_{c} U_{m}^{0} / M\right)(\text { compound })\right\} /\left(J \cdot g^{-1}\right)>-39133.6 \pm 0.9 \\
& \left(\Delta_{c} U_{m}^{0}\right) \text { (compound) } /\left(\mathrm{kJ} \cdot \mathrm{mol}^{-1}\right) \quad-7250.28 \pm 1.08 \\
& \left(\Delta_{c} H_{m}^{0} / \mathrm{M}\right) \text { (compound) } /\left(\mathrm{kJ} \cdot \mathrm{mol}^{-1}\right)-7258.33 \pm 1.08
\end{aligned}
$$

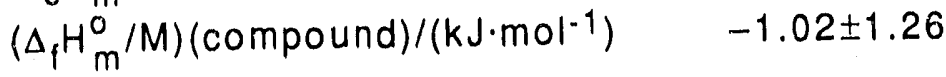


TABLE 4. Measured and calculated densities of 1,2,3,4-tetrahydro-9-methylcarbazole at saturation pressure a

\begin{tabular}{ccc}
\hline$T / K$ & $\rho / k g \cdot \mathrm{m}^{-3}$ & $10^{2}\left(\rho-\rho_{\mathrm{cs}}\right) / \rho$ \\
\hline 347.899 & 1036.30 & -0.12 \\
363.675 & 1025.20 & 0.10 \\
381.190 & 1013.40 & 0.12 \\
382.364 & 1012.00 & 0.06 \\
397.850 & 1001.00 & 0.03 \\
423.677 & 983.01 & 0.05 \\
\hline
\end{tabular}

a $\quad \rho_{\mathrm{CS}}=$ density calculated using corresponding. states \{equation ( 7$)$ \}. 
TABLE 5. Vapor-pressure results: IP refers to measurements performed with the inclined-piston gauge; water or decane refers to which material was used as the standard in the reference ebulliometer; $T$ is the temperature of the experimental inclined-piston pressure gauge measurements or, for ebulliometric measurements, of the condensation temperature of the sample; the pressure $p$ for ebulliometric measurements was calculated from the condensation temperature of the reference substance; $\Delta p$ is the difference of the calculated value of pressure from the observed value of pressure; $\sigma$ is the propagated error calculated from equations (1) and (2); $\Delta T$ is the difference between the boiling and condensation temperature. ( $T_{\text {boil }}-T_{\text {cond }}$ ) for the sample in the ebulliometer

\begin{tabular}{|c|c|c|c|c|c|}
\hline Method & $\frac{T}{K}$ & $\frac{p}{k P a}$ & $\frac{\Delta p}{k P a}$ & $\frac{\sigma(p)}{k P a}$ & $\frac{\Delta T}{K}$ \\
\hline & \multicolumn{5}{|c|}{ 9-Methylcarbazole } \\
\hline IP & 373.154 & 0.0163 & 0.0001 & 0.0002 & \\
\hline IP & 383.152 & 0.0304 & 0.0000 & 0.0002 & \\
\hline IP & 393.150 & 0.0550 & 0.0000 & 0.0002 & \\
\hline IP & 403.152 & 0.0964 & 0.0002 & 0.0002 & \\
\hline IP & 413.150 & 0.1628 & 0.0001 & 0.0002 & \\
\hline IP & 423.152 & 0.2674 & 0.0001 & 0.0002 & \\
\hline IP & 433.151 & 0.4271 & 0.0000 & 0.0003 & \\
\hline IP & 443.151 & 0.6654 & 0.0001 & 0.0003 & \\
\hline IP & 453.151 & 1.0120 & 0.0000 & 0.0004 & \\
\hline IP & 463.148 & 1.5059 & -0.0002 & 0.0004 & \\
\hline decane & 470.622 & 2.0000 & -0.0003 & 0.0001 & 0.096 \\
\hline IP & 473.153 & 2.1964 & -0.0002 & 0.0005 & \\
\hline decane & 478.494 & 2.6660 & 0.0002 & 0.0002 & 0.057 \\
\hline IP & 483.146 & 3.1420 & -0.0001 & 0.0007 & \\
\hline decane & 498.901 & 5.3330 & 0.0001 & 0.0003 & 0.032 \\
\hline decane & 511.861 & 7.9989 & 0.0001 & 0.0004 & 0.027 \\
\hline decane & 521.574 & 10.6661 & 0.0004 & 0.0005 & 0.018 \\
\hline decane & 529.426 & 13.332 & 0.000 & 0.001 & 0.011 \\
\hline decane & 537.572 & 16.665 & 0.001 & 0.001 & 0.009 \\
\hline decane & 544.338 & 19.933 & 0.000 & 0.001 & 0.010 \\
\hline decane & 553.236 & 25.023 & 0.001 & 0.001 & 0.006 \\
\hline
\end{tabular}


TABLE 5. Continued

\begin{tabular}{lccccc}
\hline Method & $\frac{T}{\mathrm{~K}}$ & $\frac{\mathrm{p}}{\mathrm{kPa}}$ & $\frac{\Delta \mathrm{p}}{\mathrm{kPa}}$ & $\frac{\sigma(\mathrm{p})}{\mathrm{kPa}}$ & $\frac{\Delta T}{\mathrm{~K}}$ \\
\hline water & 553.232 & 25.023 & 0.004 & 0.001 & 0.005 \\
water & 562.186 & 31.177 & 0.002 & 0.002 & 0.002 \\
water & 571.191 & 38.565 & 0.001 & 0.002 & 0.002 \\
water & 580.244 & 47.375 & -0.001 & 0.002 & 0.001 \\
water & 589.351 & 57.817 & -0.005 & 0.003 & 0.001 \\
water & 607.712 & 84.533 & -0.005 & 0.004 & -0.001 \\
water & 616.968 & 101.325 & -0.006 & 0.004 & -0.002 \\
water & 626.274 & 120.790 & -0.004 & 0.005 & -0.002 \\
water & 635.632 & 143.25 & 0.00 & 0.01 & -0.001 \\
water & 645.035 & 169.02 & 0.00 & 0.01 & -0.002 \\
water & 654.490 & 198.49 & 0.01 & 0.01 & 0.001 \\
water & 663.992 & 232.02 & 0.01 & 0.01 & 0.002 \\
water & 673.539 & 270.02 & 0.01 & 0.01 & 0.011
\end{tabular}

1,2,3,4-Tetrahydro-9-methylcarbazole

$\begin{array}{crrrrr}\text { IP } & 370.001 & 0.0173 & -0.0001 & 0.0002 & \\ \text { IP } & 380.000 & 0.0330 & 0.0000 & 0.0002 & \\ \text { IP } & 390.000 & 0.0598 & -0.0002 & 0.0002 & \\ \text { IP } & 400.002 & 0.1052 & -0.0001 & 0.0002 & \\ \text { IP } & 410.004 & 0.1790 & 0.0002 & 0.0002 & \\ \text { IP } & 420.006 & 0.2948 & 0.0003 & 0.0002 & \\ \text { IP } & 430.002 & 0.4719 & 0.0002 & 0.0003 & \\ \text { IP } & 439.999 & 0.7365 & 0.0004 & 0.0003 & \\ \text { IP } & 450.000 & 1.1218 & 0.0001 & 0.0004 & \\ \text { IP } & 460.001 & 1.6718 & 0.0003 & 0.0005 & \\ \text { decane } & 464.679 & 2.0000 & 0.0000 & 0.0001 & 0.095 \\ \text { IP } & 469.999 & 2.4390 & -0.0006 & 0.0006 & \\ \text { decane } & 472.428 & 2.6660 & -0.0004 & 0.0002 & 0.081 \\ \text { IP } & 475.003 & 2.9267 & 0.0003 & 0.0006 & \\ \text { decane } & 492.487 & 5.3330 & -0.0001 & 0.0003 & 0.054\end{array}$


TABLE 5. Continued

\begin{tabular}{lccccc}
\hline Method & $\frac{T}{\mathrm{~K}}$ & $\frac{\mathrm{p}}{\mathrm{kPa}}$ & $\frac{\Delta \mathrm{p}}{\mathrm{kPa}}$ & $\frac{\sigma(\mathrm{p})}{\mathrm{kPa}}$ & $\frac{\Delta \mathrm{T}}{\mathrm{K}}$ \\
\hline decane & 505.226 & 7.9989 & 0.0004 & 0.0004 & 0.032 \\
decane & 514.780 & 10.666 & 0.000 & 0.001 & 0.019 \\
decane & 522.498 & 13.332 & 0.000 & 0.001 & 0.016 \\
decane & 530.509 & 16.665 & 0.001 & 0.001 & 0.014 \\
decane & 537.161 & 19.933 & 0.001 & 0.001 & 0.011 \\
decane & 545.908 & 25.023 & 0.004 & 0.001 & 0.011 \\
water & 554.717 & 31.177 & 0.001 & 0.002 & 0.011 \\
water & 563.573 & 38.565 & -0.001 & 0.002 & 0.011 \\
water & 572.478 & 47.375 & -0.004 & 0.002 & 0.011 \\
water & 581.431 & 57.817 & -0.003 & 0.003 & 0.014 \\
water & 590.433 & 70.120 & 0.003 & 0.003 & 0.018 \\
water & 599.498 & 84.533 & -0.012 & 0.004 & 0.012 \\
water & 608.604 & 101.325 & -0.012 & 0.004 & 0.012 \\
water & 617.758 & 120.790 & -0.008 & 0.005 & 0.013 \\
water & 626.964 & 143.25 & 0.00 & 0.01 & 0.012 \\
water & 636.215 & 169.02 & 0.01 & 0.01 & 0.015 \\
water & 645.516 & 198.49 & 0.02 & 0.01 & 0.018 \\
water & 654.835 & 232.02 & 0.15 & 0.01 & 0.036 \\
\hline
\end{tabular}

a The value at this temperature was not included in the fit. 
TABLE 6. Cox equation coefficients

\begin{tabular}{lcc} 
& 9 -Methylcarbazole & $\mathbf{1 , 2 , 3 , 4 - T e t r a h y d r o - 9 - m e t h y l c a r b a z o l e ~}$ \\
Tref/K & 890 & 854 \\
Pref/kPa & 3376 & 2709 \\
$\mathrm{~A}$ & 2.58573 & 2.62775 \\
$10^{3} \mathrm{~B}$ & -1.47375 & -1.51344 \\
$10^{6} \mathrm{C}$ & 1.03310 & 1.05631 \\
$\mathrm{~T} / \mathrm{Ka}$ & 373 to 664 & 370 to 645 \\
\hline
\end{tabular}

a Temperature range of the vapor pressures used in the fit. 
TABLE 7. Enthalpies of vaporization obtained from the Cox and Clapeyron equations

\begin{tabular}{|c|c|c|c|c|c|}
\hline $\mathrm{T} / \mathrm{K}$ & $\Delta_{l}^{g} H_{m} / R K$ & $\mathrm{~T} / \mathrm{K}$ & $\Delta_{1}^{g} H_{m} / R K$ & $T / K$ & $\Delta_{1}^{g} H_{m} / R K$ \\
\hline \multicolumn{6}{|c|}{ 9-Methylcarbazole } \\
\hline $298.15^{a}$ & $9764 \pm 12$ & 460.00 & $8314 \pm 2$ & 620.00 & $6923 \pm 33$ \\
\hline $300.00^{a}$ & $9746 \pm 11$ & 480.00 & $8146 \pm 3$ & 640.00 & $6724 \pm 42$ \\
\hline $320.00 a$ & $9558 \pm 8$ & 500.00 & $7980 \pm 4$ & 660.00 & $6515 \pm 52$ \\
\hline $340.00 \mathrm{a}$ & $9372 \pm 6$ & 520.00 & $7813 \pm 7$ & $680.00 a$ & $6293 \pm 63$ \\
\hline $360.00 \mathrm{a}$ & $9188 \pm 4$ & 540.00 & $7645 \pm 10$ & $700.00 a$ & $6058 \pm 76$ \\
\hline 380.00 & $9007 \pm 3$ & 560.00 & $7473 \pm 14$ & $720.00 \mathrm{a}$ & $5806 \pm 89$ \\
\hline 400.00 & $8829 \pm 2$ & 580.00 & $7296 \pm 19$ & 740.00 a & $5536 \pm 105$ \\
\hline 420.00 & $8654 \pm 1$ & 600.00 & $7114 \pm 25$ & $760.00 \quad a$ & $5244 \pm 121$ \\
\hline 440.00 & $8482 \pm 1$ & & & & \\
\hline
\end{tabular}

\section{1,2,3,4-Tetrahydro-9-methylcarbazole}

\begin{tabular}{|c|c|c|c|c|c|}
\hline $298.15^{a}$ & $9688 \pm 18$ & 440.00 & $8368 \pm 2$ & 580.00 & $7111 \pm 25$ \\
\hline $300.00^{a}$ & $9670 \pm 18$ & 460.00 & $8194 \pm 2$ & 600.00 & $6909 \pm 33$ \\
\hline $320.00 \mathrm{a}$ & $9475 \pm 13$ & 480.00 & $8020 \pm 4$ & 620.00 & $6696 \pm 42$ \\
\hline $340.00 a$ & $9283 \pm 9$ & 500.00 & $7846 \pm 6$ & 640.00 & $6470 \pm 53$ \\
\hline $360.00 \mathrm{a}$ & $9094 \pm 6$ & 520.00 & $7670 \pm 9$ & $660.00 \quad a$ & $6230 \pm 65$ \\
\hline 380.00 & $8907 \pm 4$ & 540.00 & $7490 \pm 13$ & $680.00 \quad a$ & $5972 \pm 79$ \\
\hline 400.00 & $8724 \pm 3$ & 560.00 & $7304 \pm 18$ & $700.00 \quad a$ & $5695 \pm 94$ \\
\hline
\end{tabular}

a Values at this temperature were calculated with extrapolated vapor pressures determined from the fitted Cox coefficients. 
TABLE 8. Melting-study summary for 1,2,3,4-tetrahydrocarbazole: $F$ is the fraction melted at observed temperature $T(F) ; T_{\text {tp }}$ is the triple-point temperature; $x$ is the mole-fraction impurity; $K_{d}$ is the distribution coefficient for the impurity as defined in reference 44.

\begin{tabular}{cc}
\hline $\mathrm{F}$ & $\mathrm{T}(\mathrm{F}) / \mathrm{K}$ \\
\hline 0.1622 & 323.371 \\
0.3107 & 323.504 \\
0.5088 & 323.574 \\
0.7069 & 323.611 \\
& \\
$\mathrm{~T}_{\mathrm{tp} / \mathrm{K}}$ & 323.71 \\
$\mathrm{X}$ & 0.0015 \\
$\mathrm{~K}_{\mathrm{d}}$ & 0.057 \\
\hline
\end{tabular}


TABLE 9. Molar enthalpy measurements for 1,2,3,4-tetrahydro-9-methylcarbazole $\left(R=8.31451 \mathrm{~J} \cdot \mathrm{K}^{-1} \cdot \mathrm{mol}^{-1}\right)$

\begin{tabular}{|c|c|c|c|c|c|c|}
\hline $\mathrm{Na}^{\mathrm{a}}$ & $h^{b}$ & $\frac{T_{1}}{k}$ & $\frac{T_{f}}{K}$ & $\frac{T \operatorname{trs}}{K}$ & $\frac{\Delta_{\text {tot }} H_{m}}{R \cdot K}$ & $\frac{\Delta_{t r s} H_{m}}{R \cdot K}$ \\
\hline \multicolumn{7}{|c|}{ Single-phase measurements in $\operatorname{cr}(\mathrm{IV})$} \\
\hline 18 & 1 & 69.838 & 92.482 & & 223.99 & 0.1 \\
\hline \multicolumn{7}{|c|}{$\operatorname{cr}(I V)$ to $\operatorname{cr}(I I I)$} \\
\hline 11 & 1 & 104.003 & 113.447 & 103.8 & 117.25 & $-1.3 \epsilon$ \\
\hline 12 & 1 & 101.830 & 111.259 & & 114.95 & $-1.2 \epsilon$ \\
\hline 14 & 1 & 102.588 & 108.565 & & 73.08 & -0.1 \\
\hline 19 & 1 & 99.994 & 110.886 & & 133.12 & 0.2 \\
\hline \multirow[t]{2}{*}{20} & 1 & 103.698 & 105.498 & & 21.77 & -0.2 \\
\hline & & & & & Average: & 0.0 \\
\hline
\end{tabular}

Single-phase measurements in cr'lil)

$\begin{array}{rrrrrr}15 & 1 & 119.893 & 156.377 & 551.70 & -0.4 \\ 20 & 1 & 117.330 & 156.566 & 589.72 & 0.0\end{array}$

$\begin{array}{rllll}8 & 4 & 158.218 & 167.714 & 162.4 \\ 9 & 1 & 160.780 & 167.323 & \\ 20 & 2 & 161.989 & 166.771 & \end{array}$

$$
\operatorname{cr}(111) \text { to } \operatorname{cr}(11)
$$

$\begin{array}{rrrrr}158.218 & 167.714 & 162.4 & 247.28 & 81.7 \\ 160.780 & 167.323 & & 196.07 & 81.8 \\ 161.989 & 166.771 & & 164.53 & 81.3\end{array}$

$$
\operatorname{cr}(11) \text { to } \operatorname{cr}(1)
$$

$\begin{array}{rrrrrrr}3 & 1 & 210.106 & 220.507 & 210.4 & 222.16 & 0.0 \\ 6 & 1 & 210.186 & 213.217 & 64.27 & 0.1 \\ 7 & 1 & 204.928 & 215.197 & 220.16 & 0.1 \\ 20 & 1 & 204.373 & 214.647 & 220.16 & 0.0\end{array}$

Single-phase measurements in $\mathrm{cr}(1)$

$\begin{array}{rrrrrr}20 & 1 & 214.631 & 308.748 & 2392.40 & 0.5 \\ 5 & 1 & 282.419 & 319.204 & 1082.95 & 1.1\end{array}$


TABLE 9. Continued

\begin{tabular}{|c|c|c|c|c|c|c|}
\hline $\mathrm{Na}^{\mathrm{a}}$ & $h^{b}$ & $\frac{T_{1}}{K}$ & $\frac{T_{f}}{K}$ & $\frac{T_{\text {trs }}}{\mathrm{K}}$ & $\frac{\Delta_{\text {tot }} H_{m}}{R \cdot K}$ & $\frac{\Delta_{\mathrm{trs}} H_{m}}{R \cdot K}$ \\
\hline \multicolumn{7}{|c|}{$\operatorname{cr}(1)$ to liquid } \\
\hline 4 & 2 & 318.867 & 326.242 & 323.71 & 2013.09 & 1764.4 \\
\hline 5 & 6 & 319.147 & 326.341 & & 2007.11 & 1763.6 \\
\hline \multirow[t]{2}{*}{22} & 2 & 315.938 & 327.294 & & 2143.91 & 1764.0 \\
\hline & & & & & Average: & 1764.0 \\
\hline \multicolumn{7}{|c|}{ Single-phase measurements in liquid } \\
\hline 22 & 1 & 337.324 & 401.201 & & 2568.93 & 0.2 \\
\hline 23 & 1 & 332.654 & 421.940 & & 3643.95 & -0.3 \\
\hline 23 & 1 & 421.840 & 503.782 & & 3856.87 & -1.0 \\
\hline
\end{tabular}

a Adiabatic series number.

b Number of heating increments.

c $\Delta_{i o t} H_{m}$ is the molar energy input from the initial temperature $T_{i}$ tc the final temperature $T_{f}$.

d $\Delta_{\mathrm{trs}} \mathrm{H}_{\mathrm{m}}$ is the net molar enthalpy of transition at the transition temperature $T_{\text {trs }}$ or the excess enthalpy relative the heat-capacity curve described in the text for singlephase measurements.

$\theta$ This value was not included in the average. See text. 
TABLE 10. Molar heat capacities at vapor-saturation pressure for 1,2,3,4-tetrahydro-9methylcarbazole $\quad\left(R=8.31451 \mathrm{~J} \cdot \mathrm{K}^{-1} \cdot \mathrm{mol}^{-1}\right)^{\mathrm{a}}$

$N^{b} \quad \frac{\langle T\rangle}{K} \quad \frac{\Delta T}{K} \quad \frac{C_{\text {sat } m^{c}}}{R}$

Nb. $\quad \frac{\langle T\rangle}{K} \quad \frac{\Delta T}{K} \quad \frac{C_{\text {sat m }}{ }^{c}}{R}$

\begin{tabular}{rrrrrrrr} 
& \multicolumn{7}{c}{$c r(I V)$} \\
17 & 4.746 & 1.0470 & 0.043 & 17 & 50.591 & 5.2034 & 6.357 \\
17 & 5.677 & 0.9418 & 0.069 & 18 & 55.603 & 5.8989 & 7.014 \\
17 & 6.675 & 1.0255 & 0.114 & 17 & 56.112 & 5.8387 & 7.080 \\
17 & 7.719 & 1.0670 & 0.175 & 11 & 58.626 & 4.1179 & 7.393 \\
17 & 8.770 & 1.0383 & 0.260 & 18 & 61.259 & 5.3996 & 7.716 \\
17 & 9.599 & 1.1330 & 0.340 & 11 & 63.469 & 5.5490 & 7.987 \\
17 & 9.832 & 1.0834 & 0.366 & 18 & 66.899 & 5.8672 & 8.388 \\
17 & 10.722 & 1.1388 & 0.464 & 11 & 69.021 & 5.5475 & 8.637 \\
17 & 11.929 & 1.2814 & 0.614 & 11 & 75.141 & 6.6757 & 9.294 \\
17 & 13.265 & 1.3872 & 0.796 & 11 & 82.758 & 8.4615 & 10.062 \\
17 & 14.727 & 1.5359 & 1.011 & 14 & 85.740 & 8.4740 & 10.345 \\
17 & 16.346 & 1.7037 & 1.260 & 12 & 88.269 & 8.3014 & 10.580 \\
17 & 18.116 & 1.8408 & 1.541 & 11 & 91.055 & 8.1255 & 10.839 \\
17 & 20.073 & 2.0809 & 1.855 & 16 & 91.803 & 8.2735 & 10.906 \\
17 & 22.250 & 2.2772 & 2.204 & 19 & 92.570 & 5.1363 & 10.972 \\
17 & 24.642 & 2.5011 & 2.587 & 14 & 94.737 & 9.5149 & 11.167 \\
17 & 27.275 & 2.7636 & 2.995 & 20 & 96.156 & 15.0800 & 11.280 \\
17 & 30.194 & 3.0722 & 3.443 & 18 & 96.235 & 7.4920 & 11.309 \\
17 & 33.451 & 3.4411 & 3.934 & 12 & 97.129 & 9.3692 & 11.363 \\
17 & 37.095 & 3.8460 & 4.472 & 19 & 97.566 & 4.8526 & 11.407 \\
17 & 41.131 & 4.2269 & 5.049 & 11 & 99.553 & 8.8597 & 11.568 \\
17 & 45.617 & 4.7459 & 5.674 & 14 & 101.042 & 3.0874 & 11.706
\end{tabular}

37 
TABLE 10. Continued

\begin{tabular}{|c|c|c|c|c|c|c|c|}
\hline $\mathrm{Na}^{\mathrm{a}}$ & $\frac{<\mathrm{T}\rangle}{\mathrm{K}}$ & $\frac{\Delta T}{K}$ & $\frac{C_{\text {sat } m}{ }^{b}}{R}$ & $\mathrm{Na}^{\mathrm{a}}$ & $\frac{\langle T\rangle}{k}$ & $\frac{\Delta T}{K}$ & $\frac{C_{\text {sat } m}}{R}$ \\
\hline \multicolumn{8}{|c|}{$\operatorname{cr}(111)$} \\
\hline 20 & 106.188 & 1.3829 & 12.324 & 11 & 127.726 & 9.5790 & 14.191 \\
\hline 20 & 107.561 & 1.3721 & 12.452 & 13 & 136.338 & 14.0675 & 14.951 \\
\hline 20 & 109.714 & 2.9426 & 12.643 & 11 & 137.318 & 9.6027 & 15.036 \\
\hline 14 & 110.038 & 2.9164 & 12.642 & 9 & 137.432 & 8.8487 & 15.045 \\
\hline 19 & 112.345 & 2.9034 & 12.865 & 9 & 146.254 & 8.7994 & 15.861 \\
\hline 14 & 112.931 & 2.8718 & 12.907 & 13 & 148.152 & 9.5421 & 16.049 \\
\hline 20 & 114.257 & 6.1492 & 13.029 & 9 & 153.294 & 5.2872 & 16.554 \\
\hline 14 & 115.783 & 2.8295 & 13.170 & 13 & 156.151 & 6.4405 & 16.884 \\
\hline 19 & 117.348 & 7.0825 & 13.291 & 8 & 156.716 & 3.0104 & 16.922 \\
\hline 11 & 118.185 & 9.4715 & 13.363 & 9 & 158.380 & 4.8908 & 17.166 \\
\hline 14 & 121.533 & 8.6651 & 13.654 & 20 & 159.269 & 5.5128 & 17.304 \\
\hline 13 & 124.225 & 10.1390 & 13.883 & & & & \\
\hline \multicolumn{8}{|c|}{$\operatorname{cr}(11)$} \\
\hline 8 & 169.303 & 3.1957 & 17.635 & 3 & 194.854 & 10.1650 & 20.090 \\
\hline 20 & 171.326 & 9.1182 & 17.817 & 6 & 196.527 & 3.1165 & 20.243 \\
\hline 9 & 171.868 & 9.1014 & 17.874 & 6 & 199.620 & 3.0865 & 20.622 \\
\hline 3 & 174.924 & 9.7597 & 18.134 & 7 & 199.934 & 10.0038 & 20.651 \\
\hline 8 & 175.763 & 9.7316 & 18.224 & 20 & 200.284 & 8.1927 & 20.692 \\
\hline 20 & 180.922 & 10.0832 & 18.700 & 6 & 202.680 & 3.0551 & 20.960 \\
\hline 3 & 184.788 & 9.9696 & 19.060 & 3 & 205.029 & 10.1948 & 21.307 \\
\hline 20 & 191.088 & 10.2803 & 19.702 & 6 & 205.706 & 3.0202 & 21.397 \\
\hline 6 & 193.405 & 3.1464 & 19.210 & 6 & 208.700 & 2.9905 & 21.794 \\
\hline
\end{tabular}


TABLE 10. Continued

$$
N^{a} \quad \frac{\langle T\rangle}{K} \quad \frac{\Delta T}{K} \quad \frac{C_{\text {sat } m}{ }^{b}}{R} \quad N^{a} \quad \frac{\langle T\rangle}{K} \quad \frac{\Delta T}{K} \quad \frac{C_{\text {sat } m}{ }^{b}}{R}
$$

\begin{tabular}{rrrrrrrr}
6 & \multicolumn{7}{c}{$\operatorname{cr}(1)$} \\
7 & 214.583 & 3.0229 & 21.279 & 4 & 274.561 & 10.4150 & 26.560 \\
3 & 220.408 & 10.4389 & 21.654 & 3 & 277.568 & 10.3464 & 26.868 \\
3 & 225.726 & 10.4525 & 22.050 & 4 & 285.126 & 10.4077 & 27.640 \\
3 & 246.179 & 10.4651 & 22.914 & 4 & 295.629 & 10.3903 & 28.787 \\
3 & 256.920 & 10.3500 & 24.821 & 22 & 311.057 & 9.9639 & 30.927 \\
3 & 267.259 & 10.3482 & 25.834 & 4 & 315.002 & 7.5092 & 31.737
\end{tabular}

liquid

$\begin{array}{rrrrrrrr}4 & 330.040 & 7.5744 & 37.276 & 22 & 408.687 & 15.0648 & 43.171 \\ 5 & 331.064 & 9.4563 & 37.352 & 22 & 423.707 & 15.7639 & 44.279 \\ 22 & 332.311 & 10.0501 & 37.441 & 22 & 439.763 & 16.4316 & 45.449 \\ 4 & 338.924 & 10.1763 & 37.935 & 22 & 456.023 & 16.1835 & 46.618 \\ 21 & 346.943 & 12.0966 & 38.538 & 22 & 472.034 & 15.9534 & 47.743 \\ 21 & 359.950 & 13.9029 & 39.512 & 22 & 488.242 & 16.6033 & 48.878 \\ 21 & 374.232 & 14.6566 & 40.589 & 22 & 504.640 & 16.3726 & 50.027 \\ 21 & 389.250 & 15.3790 & 41.716 & 22 & 517.830 & 10.1003 & 50.999 \\ 21 & 404.501 & 15.1317 & 42.857 & & & & \end{array}$

a Measurements spanning transition temperatures are not included in this table. These are listed in table 9.

b Adiabatic series number.

c Average heat capacity for a temperature increment of $\Delta T$ with a mean temperature $\langle T\rangle$. 
TABLE 11. Experimental $C_{x, m^{\prime \prime}}^{\prime \prime}$ values $\quad\left(R=8.31451 \mathrm{~J} \cdot \mathrm{K}^{-1} \cdot \mathrm{mol}^{-1}\right)$

\begin{tabular}{|c|c|c|c|c|c|c|}
\hline mass $/ g$ & 0.010714 & 0.018054 & $0.0,29730$ & 0.009255 & 0.028222 & 0.021491 \\
\hline Vol. cell/ $/ \mathrm{cm}^{3}$ a & 0.05387 & 0.05570 & 0.05409 & 0.05288 & 0.05288 & 0.05288 \\
\hline $\mathrm{T} / \mathrm{K}$ & $C_{x, m^{\prime R}}^{\prime l}$ & $C_{x, m^{\prime A}}^{\prime l}$ & $C_{x, m}^{\prime l} / R$ & $C_{x, m}^{\| l}$ & $C_{x, m^{\prime R}}^{\prime \prime}$ & $C_{x, m}^{\prime l} / R$ \\
\hline
\end{tabular}

$1,2,3,4-$ Tetrahydro-9-methylcarbazole

9-Methylcarbazole

$\begin{array}{llll}335.0 & 37.3 & 37.5 & 37.1 \\ 355.0 & 39.2 & 38.9 & 38.9 \\ 375.0 & 40.5 & 40.6 & 40.3 \\ 395.0 & 43.1 & 42.3 & 42.1 \\ 415.0 & 43.6 & 43.8 & 43.4 \\ 435.0 & 45.1 & 45.2 & 44.8 \\ 455.0 & 47.7 & 46.8 & 46.5 \\ 475.0 & 48.3 & 48.1 & 47.9 \\ 495.0 & 50.5 & 49.4 & 49.4 \\ 515.0 & 51.4 & 50.9 & 50.6 \\ 535.0 & 53.1 & 52.2 & 52.4 \\ 555.0 & 54.9 & 53.9 & 53.5 \\ 575.0 & 56.0 & 55.4 & 54.6 \\ 595.0 & 57.4 & 56.6 & 56.2 \\ 615.0 & 60.0 & 57.8 & 57.0 \\ 635.0 & 61.5 & 59.0 & 58.6 \\ 655.0 & 63.1 & 61.0 & 59.3 \\ 675.0 & & & \\ 695.0 & & & \\ 715.0 & & & \\ 735.0 & & & \\ 755.0 & & & \end{array}$

38.5

37.7

37.5

39.9

39.0

38.8

41.0

40.2

39.9

42.2

41.4

41.2

43.4

42.1

42.3

44.9

43.5

43.4

45.6

44.7

44.3

47.0

45.9

45.8

48.5

47.0

47.1

49.7

47.9

48.1

50.3

49.1

48.8

51.8

50.4

50.2

54.0

51.1

51.3

55.0

51.9

52.4

57.0

52.9

53.6

58.3

54.2

54.4

59.7

55.3

55.2

60.7

55.9

56.2

62.9

56.9

57.0

65.6

57.6

57.8

a Volume measured at $298.15 \mathrm{~K}$. 
TABLE 12. Parameters for equations (13) and (14), estimated critical constants and acentric factor for 9-methylcarbazole and 1,2,3,4-tetrahydro-9l. 1ethylcarbazole a

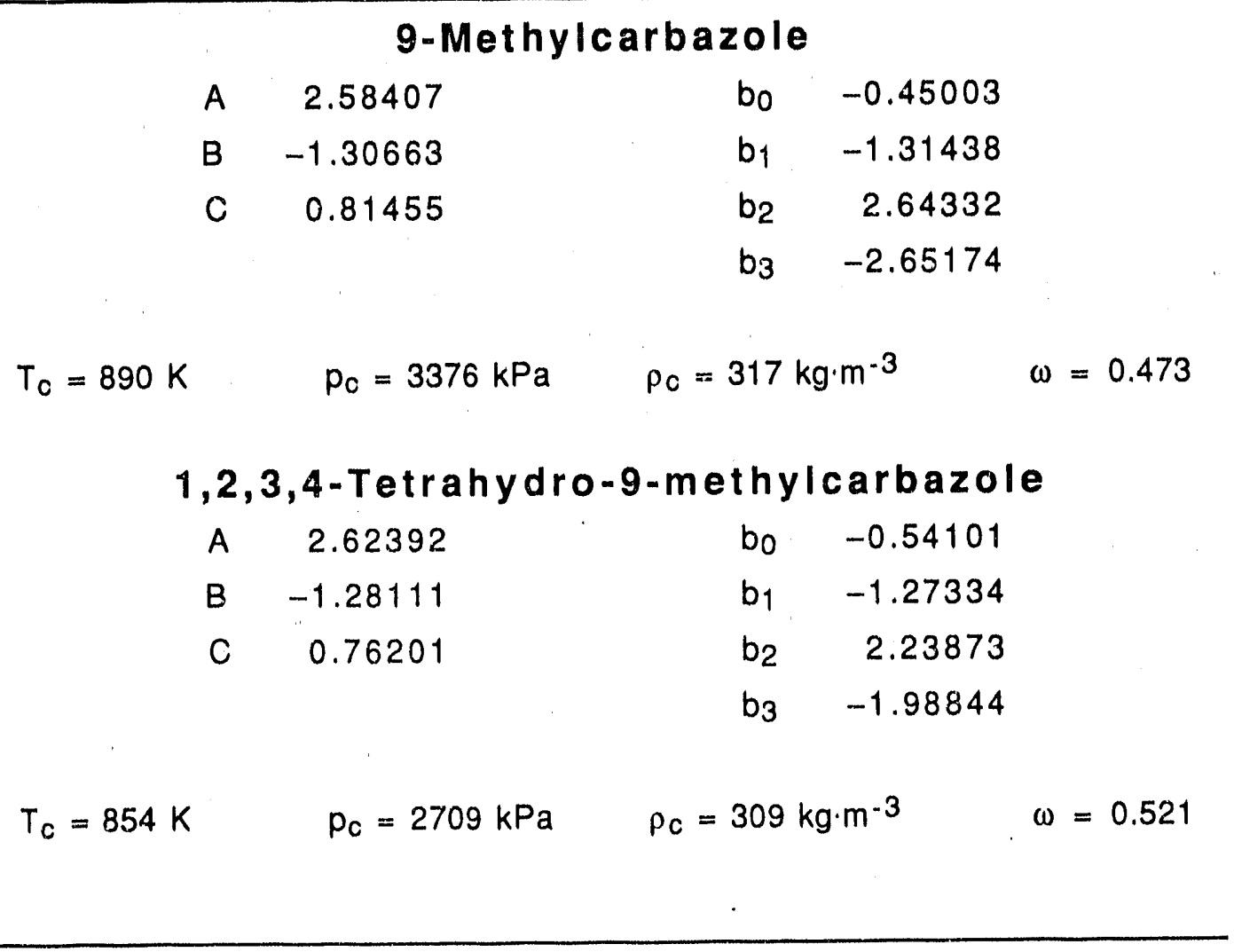

a Values for the critizal constants and acentric factor are estimates derived from the fitting procedures (see text). 
TABLE 13. Values of $C_{v, m}^{\| l}\left(\rho=\rho_{\text {sat }}\right) / R$ and $C_{\text {sat, } m} / R \quad\left(R=8.31451 \mathrm{~J} \cdot \mathrm{K}^{-1} \cdot \mathrm{mol}^{-1}\right)$

$T / K \quad C_{v, m}^{l l}\left(p=\rho_{s a t}\right) / R \quad C_{s a t, m} / R \quad T / K \quad C_{v, m}^{l l}\left(\rho=\rho_{s a t}\right) / R \quad C_{s a t, m} / R$

\begin{tabular}{|c|c|c|c|c|c|}
\hline \multicolumn{6}{|c|}{ 9-Methylcarbazole } \\
\hline 370.0 & 37.6 & 37.6 & 570.0 & 48.5 & 48.5 \\
\hline 390.0 & 38.7 & 38.7 & 590.0 & 49.6 & 49.6 \\
\hline 410.0 & 39.7 & 39.7 & 610.0 & 50.6 & 50.7 \\
\hline 430.0 & 40.8 & 40.8 & 630.0 & 51.7 & 51.7 \\
\hline 450.0 & 41.9 & 41.9 & 650.0 & 52.6 & 52.7 \\
\hline 470.0 & 43.0 & 43.0 & 670.0 & 53.6 & 53.6 \\
\hline 490.0 & 44.1 & 44.1 & 690.0 & 54.4 & 54.5 \\
\hline 510.0 & 45.2 & 45.2 & 710.0 & 55.1 & 55.3 \\
\hline 530.0 & 46.3 & 46.3 & 730.0 & 55.8 & 56.0 \\
\hline 550.0 & 47.4 & 47.4 & 750.0 & 56.3 & 56.7 \\
\hline \multicolumn{6}{|c|}{$1,2,3,4-$ Tetrahydro-9-methylcarbazole } \\
\hline 330.0 & 37.3 & 37.3 & 510.0 & 50.4 & 50.4 \\
\hline 350.0 & 38.8 & 38.8 & 530.0 & 51.8 & 51.8 \\
\hline 370.0 & 40.3 & 40.3 & 550.0 & 53.1 & 53.1 \\
\hline 390.0 & 41.8 & 41.8 & 570.0 & 54.4 & 54.5 \\
\hline 410.0 & 43.3 & 43.3 & 590.0 & 55.7 & 55.7 \\
\hline 430.0 & 44.7 & 44.7 & 610.0 & 56.9 & 56.9 \\
\hline 450.0 & 46.2 & 46.2 & 630.0 & 58.0 & 58.1 \\
\hline 470.0 & 47.6 & 47.6 & 650.0 & 59.1 & 59.1 \\
\hline 490.0 & 49.0 & 49.0 & & & \\
\hline
\end{tabular}


TABLE 14. Molar thermodynamic functions at vapor-saturation pressure for $1,2,3,4$ tetrahydro-9-methylcarbazole $\quad\left(R=8.31451 \mathrm{~J} \cdot \mathrm{K}^{-1} \cdot \mathrm{mol}^{-1}\right)$

\begin{tabular}{|c|c|c|c|c|c|c|c|}
\hline$\frac{T}{K}$ & $\frac{C_{\text {sat, } m}}{R}$ & $\frac{\Delta_{0}^{\top} S_{m}^{0}}{R}$ & $\frac{\Delta_{0}^{T} H_{m}^{0}}{\mathrm{RT}}$ & $\frac{T}{K}$ & $\frac{C_{\text {sat } m}}{R}$ & $\frac{\Delta_{0}^{T} S_{m}^{0}}{R}$ & $\frac{\Delta_{0}^{T} H_{m}^{0}}{R T}$ \\
\hline \multicolumn{8}{|c|}{$\operatorname{cr}(I V)$} \\
\hline 5.000 & 0.047 & 0.016 & 0.012 & 60.000 & 7.563 & 5.547 & 3.414 \\
\hline 10.000 & 0.384 & 0.127 & 0.096 & 65.000 & 8.171 & 6.177 & 3.757 \\
\hline 15.000 & 1.052 & 0.402 & 0.297 & 70.000 & 8.745 & 6.803 & 4.093 \\
\hline 20.000 & 1.843 & 0.812 & 0.584 & 75.000 & 9.280 & 7.425 & 4.421 \\
\hline 25.000 & 2.643 & 1.309 & 0.916 & 80.000 & 9.790 & 8.040 & 4.741 \\
\hline 30.000 & 3.413 & 1.859 & 1.268 & 85.000 & 10.277 & 8.649 & $5.0,52$ \\
\hline 35.000 & 4.165 & 2.442 & 1.628 & 90.000 & 10.743 & 9.249 & 5.355 \\
\hline 40.000 & 4.889 & 3.046 & 1.991 & 95.000 & 11.188 & 9.842 & 5.651 \\
\hline 45.000 & 5.589 & 3.662 & 2.352 & 100.000 & 11.612 & 10.427 & 5.938 \\
\hline 50.000 & 6.277 & 4.287 & 2.710 & $102.000 \mathrm{a}$ & 11.787 & 10.659 & 6.051 \\
\hline 55.000 & 6.938 & 4.916 & 3.065 & $103.800^{a}$ & 11.951 & $10: 866$ & 6.152 \\
\hline
\end{tabular}

$$
\operatorname{cr}(111)
$$

$\begin{array}{llllllll}103.800 \text { a } & 12.119 & 10.866 & 6.152 & 150.000 & 16.213 & 16.024 & 8.610 \\ 105.000 & 12.223 & 11.006 & 6.221 & 153.000 & 16.514 & 16.348 & 8.762 \\ 110.000 & 12.658 & 11.585 & 6.504 & 156.000 & 16.848 & 16.672 & 8.914 \\ 120.000 & 13.523 & 12.723 & 7.052 & 158.000 & 17.114 & 16.888 & 9.016 \\ 130.000 & 14.384 & 13.840 & 7.583 & 160.000 \text { a } & 17.436 & 17.105 & 9.120 \\ 140.000 & 15.278 & 14.938 & 8.101 & 162.000 \text { a } & 17.814 & 17.324 & 9.225 \\ 145.000 & 15.739 & 15.482 & 8.356 & 162.400 \text { a } & 17.896 & 17.368 & 9.246\end{array}$

$$
\operatorname{cr}(11)
$$

\begin{tabular}{|c|c|c|c|c|c|c|c|}
\hline $162.400 \mathrm{a}$ & 17.253 & 17.871 & 9.749 & 195.000 & 20.080 & 21.254 & 11.218 \\
\hline $164.000 \mathrm{a}$ & 17.340 & 18.041 & 9.823 & 200.000 & 20.668 & 21.770 & 11.447 \\
\hline $166.000 \mathrm{a}$ & 17.444 & 18.252 & 9.914 & 202.000 & 20.920 & 21.977 & 11.539 \\
\hline 168.000 & 17.558 & 18.461 & 10.004 & 204.000 & 21.175 & 22.184 & 11.632 \\
\hline 170.000 & 17.697 & 18.670 & 10.094 & 206.000 & 21.433 & 22.392 & 11.726 \\
\hline 175.000 & 18.145 & 19.189 & 10.317 & 208.000 & 21.698 & 22.600 & 11.821 \\
\hline
\end{tabular}


TABLE 14. continued

\begin{tabular}{|c|c|c|c|c|c|c|c|}
\hline$\frac{T}{K}$ & $\frac{\mathrm{C}_{\text {sat } \mathrm{m}}}{\mathrm{R}}$ & $\frac{\Delta_{0}^{\top} S_{m}^{0}}{R}$ & $\frac{\Delta_{0}^{\top} H_{m}^{0}}{P_{1} !}$ & $\frac{T}{K}$ & $\frac{C_{\text {sat } m}}{R}$ & $\frac{\Delta_{0}^{\top} S_{m}^{0}}{R}$ & $\frac{\Delta_{0}^{T} H_{m}^{0}}{R T}$ \\
\hline \multicolumn{8}{|c|}{ cr(II) continued } \\
\hline 180.000 & 18.615 & 19.707 & 10.541 & $210.000 a$ & 21.983 & 22.809 & 11.916 \\
\hline 185.000 & 19.095 & 20.223 & 10.766 & $210.400 a$ & 22.043 & 22.851 & 11.936 \\
\hline 190.000 & 19.585 & 20.739 & 10.991 & & & & \\
\hline \multicolumn{8}{|c|}{$\operatorname{cr}(1)$} \\
\hline 210.400 a & 21.036 & 22.851 & 11.936 & 280.000 & 27.090 & 29.618 & 14.891 \\
\hline 215.000 & 21.305 & 23.309 & 12.133 & 290.000 & 28.124 & 30.586 & 15.329 \\
\hline 220.000 & 21.633 & 23.802 & 12.345 & 298.150 & 29.027 & 31.378 & 15.691 \\
\hline 230.000 & 22.391 & 24.780 & 12.765 & 300.000 & 29.244 & 31.558 & 15.774 \\
\hline 240.000 & 23.251 & 25.751 & 13.184 & 310.000 & 30.486 & 32.537 & 16.228 \\
\hline 250.000 & 24.162 & 26.719 & 13.605 & $320.000 a$ & 31.872 & 33.526 & 16.695 \\
\hline 260.000 & 25.111 & 27.685 & 14.029 & $323.710 \mathrm{a}$ & 32.429 & 33.897 & 16.872 \\
\hline 270.000 & 26.092 & 28.651 & 14.457 & & & & \\
\hline
\end{tabular}

liquid

$\begin{array}{llllllll}298.150 \text { a } & 34.953 & 36.396 & 21.159 & 480.000 & 48.301 & 55.987 & 28.931 \\ 300.000 \text { a } & 35.085 & 35.613 & 21.245 & 500.000 & 49.700 & 57.987 & 29.734 \\ 320.000 \text { a } & 36.535 & 38.923 & 22.155 & 520.000 & 51.141 & 59.965 & 30.530 \\ 323.710 \text { a } & 36.808 & 39.346 & 22.321 & 540.000 & 52.477 & 61.920 & 31.318 \\ 340.000 & 38.016 & 41.183 & 23.044 & 560.000 & 53.805 & 63.852 & 32.097 \\ 360.000 & 39.516 & 43.398 & 23.918 & 580.000 & 55.091 & 65.763 & 32.868 \\ 380.000 & 41.022 & 45.575 & 24.778 & 600.000 & 56.327 & 67.652 & 33.630 \\ 400.000 & 42.521 & 47.717 & 25.628 & 620.000 & 57.504 & 69.518 & 34.381 \\ 420.000 & 44.006 & 49.828 & 26.468 & 640.000 & 58.610 & 71.361 & 35.121 \\ 440.000 & 45.467 & 51.909 & 27.298 & 660.000 & 59.659 & 73.181 & 35.849 \\ 460.000 & 46.898 & 53.962 & 28.120 & & & & \end{array}$

a Values at this temperature were calculated with graphically extrapolated heat capacities. 
TABLE 15. Thermodynamic propertles in the ideal-gas state.

$$
\left(R=8.31451 \mathrm{~J} \cdot \mathrm{K}^{-1} \cdot \mathrm{mol}^{-1} \text { and } \mathrm{p}^{\circ}=101.325 \mathrm{kPa}\right)
$$

\begin{tabular}{|c|c|c|c|c|c|c|c|}
\hline$\frac{T}{K}$ & $\frac{\Delta_{0}^{T} H_{m}^{\circ}}{R \cdot T}$ & $\frac{\Delta \mathrm{Imp}_{\mathrm{m}} \mathrm{H}_{\mathrm{m}}^{\circ}}{\mathrm{R} T}$ & $\frac{\Delta_{0}^{T} s_{m}^{0}}{R}$ & $\frac{\Delta{ }_{i m p} s_{m}^{0}}{A}$ & $\frac{\Delta H_{m}^{\circ}}{R T}$ & $\frac{\Delta s_{m}^{0}}{R}$ & $\frac{\Delta G_{m}^{0}}{R T}$ \\
\hline \multicolumn{8}{|c|}{ 9-Methylcarbazole } \\
\hline $298.15 \quad 0, d$ & $52.00 \pm 0.04$ & 0.00 & $50.29 \pm 0.05$ & 0.00 & $80.31 \pm 0.21$ & $-56.58 \pm 0.05$ & $136.89 \pm 0.20$ \\
\hline $300.00 \quad 0, d$ & $51.83 \pm 0.04$ & 0.00 & $50.44 \pm 0.05$ & 0.00 & $79.76 \pm 0.20$ & $-56.64 \pm 0.05$ & $136.39 \pm 0.20$ \\
\hline $320.000, d$ & $50.15 \pm 0.03$ & 0.00 & $52.05 \pm 0.04$ & 0.00 & $74.16 \pm 0.19$ & $-57.28 \pm 0.04$ & $131.43 \pm 0.19$ \\
\hline $340.00 \quad 0, d$ & $48.73 \pm 0.03$ & 0.00 & $53.63 \pm 0.04$ & 0.00 & $69.22 \pm 0.18$ & $-57.87 \pm 0.04$ & $127.09 \pm 0.18$ \\
\hline $360.000, \mathrm{~d}$ & $47.54 \pm 0.02$ & 0.00 & $55.19 \pm 0.04$ & 0.00 & $64.83 \pm 0.17$ & $-58.43 \pm 0.04$ & $123.26 \pm 0.17$ \\
\hline 380.00 & $46.54 \pm 0.02$ & 0.00 & $56.73 \pm 0.04$ & 0.00 & $60.92 \pm 0.16$ & $-58.94 \pm 0.04$ & $119.86 \pm 0.16$ \\
\hline 400.00 & $45.71 \pm 0.02$ & 0.00 & $58.26 \pm 0.04$ & 0.00 & $57.41 \pm 0.15$ & $-59.42 \pm 0.04$ & $116.83 \pm 0.16$ \\
\hline 420.00 & $45.01 \pm 0.03$ & 0.00 & $59.77 \pm 0.05$ & $0.00^{\circ}$ & $54.25 \pm 0.15$ & $-59.85 \pm 0.05$ & $114.10 \pm 0.15$ \\
\hline 440.00 & $44.43 \pm 0.04$ & 0.01 & $61.28 \pm 0.06$ & 0.00 & $51.39 \pm 0.14$ & $-60.26 \pm 0.06$ & $111.64 \pm 0.15$ \\
\hline 460,00 & $43.96 \pm 0.06$ & 0.01 & $62.77 \pm 0.07$ & 0.01 & $48.80 \pm 0.14$ & $-60.62 \pm 0.07$ & $109.42 \pm 0.16$ \\
\hline 480.00 & $43.58 \pm 0.07$ & 0.02 & $64.25 \pm 0.09$ & 2.01 & $46.43 \pm 0.14$ & $-60.96 \pm 0.09$ & $107.39 \pm 0.17$ \\
\hline 500.00 & $43.27 \pm 0.09$ & 0.02 & $65.72 \pm 0.10$ & 0.02 & $44.27 \pm 0.15$ & $-61.27 \pm 0.10$ & $105.54 \pm 0.18$ \\
\hline 520.00 & $43.04 \pm 0.10$ & 0.04 & $67.18 \pm 0.12$ & 0.03 & $42.29 \pm 0.15$ & $-61.55 \pm 0.12$ & $103.84 \pm 0.19$ \\
\hline 540.00 & $42.87 \pm 0.11$ & 0.05 & $68.63 \pm 0.14$ & 0.04 & $40.47 \pm 0.16$ & $-61.81 \pm 0.14$ & $102.28 \pm 0.21$ \\
\hline 560.00 & $42.75 \pm 0.13$ & 0.07 & $70.06 \pm 0.15$ & 0.06 & $38.80 \pm 0.17$ & $-62.04 \pm 0.15$ & $100.84 \pm 0.22$ \\
\hline 580.00 & $42.67 \pm 0.14$ & 0.10 & $71.49 \pm 0.17$ & 0.08 & $37.25 \pm 0.18$ & $-62.25 \pm 0.17$ & $99.51 \pm 0.24$ \\
\hline 600.00 & $42.64 \pm 0.16$ & 0.14 & $72.90 \pm 0.19$ & 0.10 & $35.82 \pm 0.18$ & $-62.44 \pm 0.19$ & $98.27 \pm 0.26$ \\
\hline 620.00 & $42.63 \pm 0.17$ & 0.18 & $74.30 \pm 0.21$ & 0.13 & $34.50 \pm 0.20$ & $-62.61 \pm 0.21$ & $97.11 \pm 0.28$ \\
\hline 640.00 & $42.66 \pm 0.19$ & 0.23 & $75.68 \pm 0.23$ & 0.17 & $33.27 \pm 0.21$ & $-62.77 \pm 0.23$ & $96,03 \pm 0,29$ \\
\hline 660.00 & $42.72 \pm 0.20$ & 0.29 & $77.05 \pm 0.25$ & 0.21 & $32.12 \pm 0.22$ & $-62.91 \pm 0.25$ & $95.03 \pm 0.31$ \\
\hline 680.00 & $42.79 \pm 0.22$ & 0.36 & $78.40 \pm 0.27$ & 0.27 & $31.05 \pm 0.23$ & $-63.03 \pm 0.27$ & $94.08 \pm 0.33$ \\
\hline 700.00 & $42.88 \pm 0.23$ & 0.44 & $79.74 \pm 0.29$ & 0.33 & $30.04 \pm 0.25$ & $-63.15 \pm 0.29$ & $93.19 \pm 0.35$ \\
\hline 720.00 & $42.98 \pm 0.25$ & 0.53 & $81.06 \pm 0.31$ & 0.40 & $29.10 \pm 0.27$ & $-63.26 \pm 0.31$ & $92.35 \pm 0.36$ \\
\hline 740.00 & $43.09 \pm 0.27$ & 0.64 & $82.35 \pm 0.33$ & 0.47 & $28.20 \pm 0.28$ & $-63.36 \pm 0.33$ & $91.56 \pm 0.38$ \\
\hline 760.00 & $43.19 \pm 0.29$ & 0.75 & $83.61 \pm 0.35$ & 0.56 & $27.34 \pm 0.30$ & $-63.47 \pm 0.35$ & $90.81 \pm 0.40$ \\
\hline
\end{tabular}


TABLE 15. Continued

\begin{tabular}{|c|c|c|c|c|c|c|c|}
\hline$\frac{T}{K}$ & $\frac{\Delta_{0}^{T} H_{m}^{0}}{R T}$ & $\frac{\Delta \mathrm{imp}_{\mathrm{m}} \mathrm{H}_{\mathrm{m}}^{0}}{R \mathrm{~T}}$ & $\frac{\Delta_{0}^{\top} S_{m}^{0}}{R}$ & $\frac{\Delta i m p S_{m}^{0}}{R}$ & $\frac{\Delta_{\Delta} H_{m}^{\prime \prime}}{R T}$ & $\frac{\Delta S_{m}^{\circ}}{R}$ & $\frac{\Delta G_{m}^{\circ}}{R T}$ \\
\hline & \multicolumn{6}{|c|}{$1,2,3,4-$ Tetrahydro-9-methylcarbazole } & \\
\hline $298,150, d$ & $53.65 \pm 0.06$ & 0.00 & $54.12 \pm 0.07$ & 0.00 & $37.55 \pm 0.14$ & $-84.15 \pm 0.07$ & $121.70 \pm 0.13$ \\
\hline $300,00 \mathrm{cid}$ & $53.48 \pm 0.06$ & 0.00 & $54.28 \pm 0.07$ & 0.00 & $37.22 \pm 0.14$ & $-84.25 \pm 0.07$ & $121.47 \pm 0.13$ \\
\hline $320.00 \quad 0, d$ & $51.76 \pm 0.05$ & 0.00 & $55.96 \pm 0.06$ & 0.00 & $33.91 \pm 0.13$ & $-85.26 \pm 0.06$ & $119.17 \pm 0.12$ \\
\hline 340.000 & $50.35 \pm 0.04$ & 0.00 & $57.64 \pm 0.05$ & 0.00 & $31.02 \pm 0.11$ & $-86.18 \pm 0.05$ & $117.21 \pm 0.12$ \\
\hline $360.00 \mathrm{c}$ & $49.18 \pm 0.03$ & 0.00 & $59.31 \pm 0.05$ & 0.00 & $28.48 \pm 0.11$ & $-87.02 \pm 0.05$ & $115.51 \pm 0.11$ \\
\hline 380.00 & $48.22 \pm 0.03$ & 0.00 & $60.99 \pm 0.05$ & 0.00 & $26.24 \pm 0.10$ & $-87.79 \pm 0.05$ & $114.03 \pm 0.11$ \\
\hline 400.00 & $47.44 \pm 0.03$ & 0.00 & $62.66 \pm 0.05$ & 0.00 & $24.26 \pm 0.10$ & $-88.48 \pm 0.05$ & $112.73 \pm 0.11$ \\
\hline 420.00 & $46.82 \pm 0.03$ & 0.00 & $64.34 \pm 0.05$ & 0.00 & $22.50 \pm 0.09$ & $-89.09 \pm 0.05$ & $111.59 \pm 0.10$ \\
\hline 440.00 & $46.32 \pm 0.03$ & 0.01 & $66.01 \pm 0.05$ & 0.01 & $20.93 \pm 0.09$ & $-89.65 \pm 0.05$ & $110.58 \pm 0.10$ \\
\hline 460.00 & $45.94 \pm 0.03$ & 0.01 & $67.68 \pm 0.05$ & 0.01 & $19.53 \pm 0.08$ & $-90.16 \pm 0.05$ & $109.69 \pm 0.10$ \\
\hline 480.00 & $45.66 \pm 0.03$ & 0.02 & $69.34 \pm 0.06$ & 0.02 & $18.27 \pm 0.08$ & $-90.61 \pm 0.06$ & $108.88 \pm 0.10$ \\
\hline 500.00 & $45.46 \pm 0.03$ & 0.03 & $71.00 \pm 0.06$ & 0.02 & $17.14 \pm 0.08$ & $-91.02 \pm 0.06$ & $108.16 \pm 0.10$ \\
\hline 520.00 & $45.33 \pm 0.04$ & 0.05 & $72.65 \pm 0.06$ & 0.04 & $16.12 \pm 0.08$ & $-91.39 \pm 0.06$ & $107.51 \pm 0.10$ \\
\hline 540.00 & $45.26 \pm 0.04$ & 0.07 & $74.29 \pm 0.07$ & 0.05 & $15.20 \pm 0.08$ & $-91.72 \pm 0.07$ & $106.91 \pm 0.10$ \\
\hline 560.00 & $45.24 \pm 0.06$ & 0.10 & $75.92 \pm 0.08$ & 0.07 & $14.36 \pm 0.09$ & $-92.02 \pm 0.08$ & $106.38 \pm 0.11$ \\
\hline 580.00 & $45.26 \pm 0.08$ & 0.13 & $77.53 \pm 0.09$ & 0.10 & $13.60 \pm 0.10$ & $-92.28 \pm 0.09$ & $105.88 \pm 0.12$ \\
\hline 600.00 & $45.32 \pm 0.10$ & 0.18 & $79.13 \pm 0.11$ & 0.13 & $12.91 \pm 0.11$ & $-92.52 \pm 0.11$ & $105.43 \pm 0.14$ \\
\hline 620.00 & $45.42 \pm 0.12$ & 0.23 & $80.71 \pm 0.13$ & 0.17 & $12.27 \pm 0.13$ & $-92.75 \pm 0.13$ & $105.02 \pm 0.16$ \\
\hline 640.00 & $45.53 \pm 0.14$ & 0.30 & $82.27 \pm 0.15$ & 0.22 & $11.69 \pm 0.15$ & $-92.95+0.15$ & $104.64 \pm 0.18$ \\
\hline 660.00 & $45.67 \pm 0.16$ & 0.38 & $83.81 \pm 0.18$ & 0.28 & $11.15 \pm 0.17$ & $-93.13 \pm 0.18$ & $104.28 \pm 0.20$ \\
\hline
\end{tabular}

a Gas-imperfection correction to the ideal-gas enthalpy.

b Gas-imperfection correction to the ideal-gas entropy.

c Values at this temperature were calculated with extrapolated vapor pressures calculated from the fitted Cox coefficients.

d Values at this temperature were calculated with graphically extrapolated values of the liquid-phase heat capacities. 

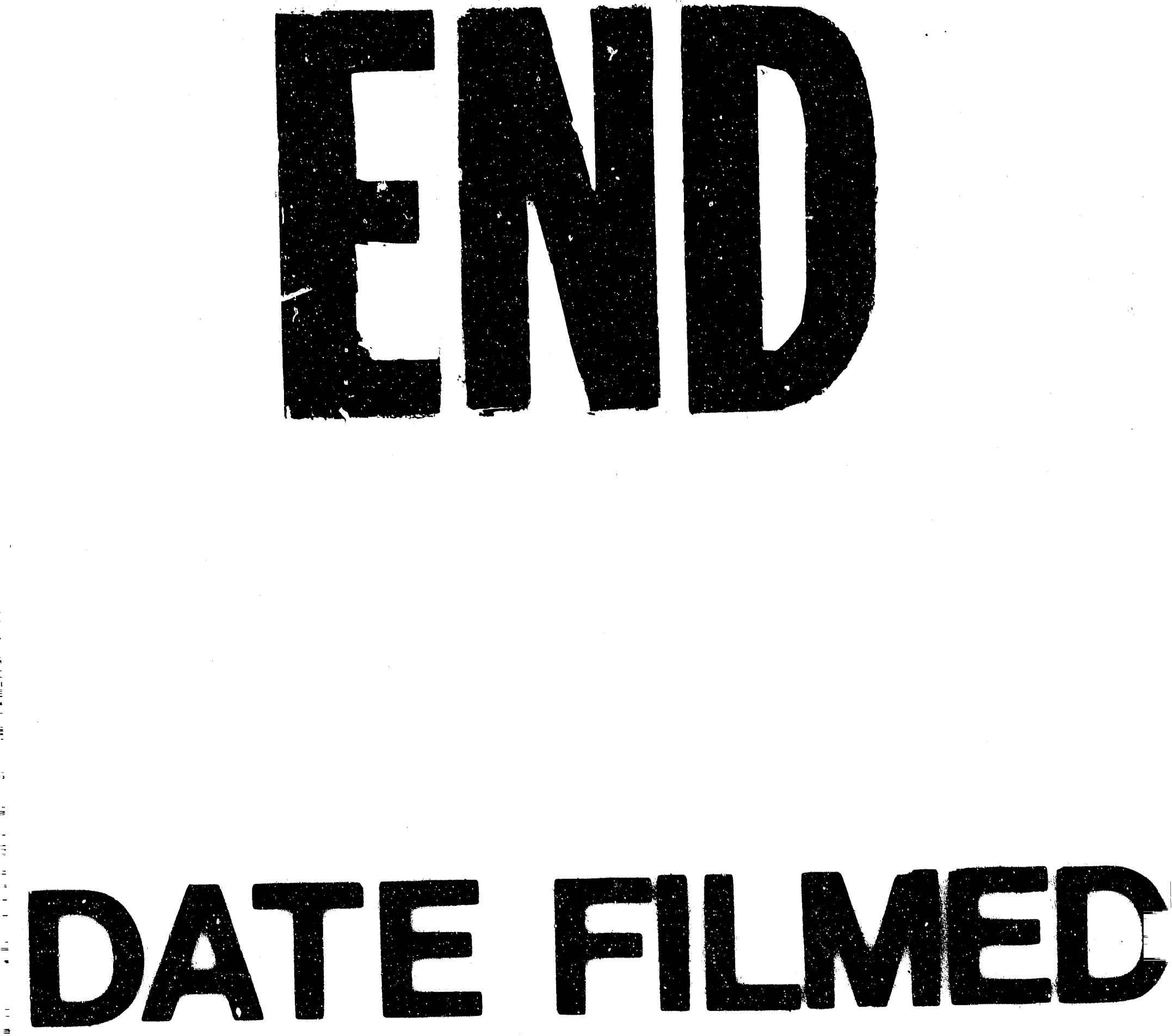$$
\text { . }
$$$$
\text { . }
$$ 
